\title{
De mediación sin intérpretes a escribanos bilingües. Diglosia, bilingüismo y escritura en la provincia de Chayanta (Potosí) durante la República boliviana (1830-1950)
}

\section{Tristan Platt}

University of St Andrews

tp@st-andrews.ac.u

RESUMEN

El bilingüismo en la Bolivia temprano-republicana permitió a los magistrados prescindir de intérpretes. Los jueces de Paz y de Letras en la provincia de Chayanta (Potosi) funcionaban como escribanos bilingües en aimara y español, y nuevos recaudadores ciudadanos bilingües reemplazaban a los curacas hereditarios de las parcialidades en Macha, todas "cerradas al aimara». A diferencia del Perú y Ecuador, donde el tributo se eliminó en los años 1850, en Bolivia se pagaba semestralmente a la Prefectura hasta fines del siglo XX. Con la Guerra Federal de 1899, los ayllus de Chayanta recuperaron los curacazgos y el idioma de Macha cambió del aimara al quechua. El artículo examina la resurgencia de los curacas recaudadores de Macha Alasaya durante el siglo $X X$. Analfabetos y monolingües en quechua, contaban con apoyo popular y recurrían a escribanos bilingües y a sus hijos para llevar adelante la administración. Formaron un archivo como constancia de sus gestiones, fuente excepcional para una etnohistoria politica de la «literacidad» rural, los movimientos sociales y las relaciones ayllu - Estado en el siglo XX. Entre los 740 documentos, se incluyen tres circulares procedentes de La Paz, escritas entre 1936 y 1946 en un dialecto aimarizado del español. Estos «pasquines» echan luz sobre el pensamiento político comunal en un período en el cual 
se intentaba recuperar el «pacto Estado - ayllu» y la «ley india», antes y después de la Revolución de 1952.

Palabras clave: bilingüismo, curacas, escribanos, archivos indigenas, literacidad.

\section{From mediation without interpreters to bilingual scribes. Diglossia, bilingualism and writing in the province of Chayanta (Potosí) during Bolivian Republic (1830-1950)}

\section{ABSTRACT}

Bilingualism made interpreters unnecessary in early Republican Bolivia. Citizen judges of the Peace functioned as Spanish-Aymara bilingual scribes in Chayanta Province (Potosi), while new bilingual Citizen tribute-collectors (recaudadores) replaced hereditary Aymara-speaking moiety Curacas. In Peru and Ecuador tribute was abolished in the 1850s, but in Bolivia it continued till the $21^{\text {st }}$ century. By the $20^{\text {th }}$ century, Quechua had become the language of the Macha Ayllu, and the moieties took back the Curacazgos. This article examines the resurgence of the moiety Curaca Recaudadores, and their persistence as tribute'collectors for most of the $20^{\text {th }}$ century. Macha moiety Curacas were illiterate, and monolingual in Quechua, but had Ayllu support, and could administer using bilingual mestizo scribes. They formed a Spanish-language Archive, an invaluable source for building a Republican ethnohistory of $20^{\text {th }}$ century rural literacy, Ayllu organization, social movements and Ayllu-State relations. Among its 740 documents the Archive contains three Aymara-influenced circulars from La Paz, written in a Spanish-derived linguistic amalgam between 1936 and 1946. They shed light on indian political thought in a period when the AylluState pact and «indian law» were being recovered, before and after the Revolution of 1952.

Keywords: bilingualism, Curacas, scribes, indigenous archives, literacy. 
Antes del nacimiento de las Repúblicas andinas, ya iba menguando la importancia de los intérpretes calificados, imprescindibles en los primeros siglos de la invasión europea. La expulsión de los jesuitas (1767), la secuela de las grandes rebeliones (1780-1782) y el impacto de la Constitución de Cádiz (1812) desplazaron la atención de los gobernantes, desde los problemas de la traducción entre los idiomas amerindios y el español hacia la supuesta necesidad de reemplazar a los primeros por el segundo. Pero, al mismo tiempo, las condiciones de la mediación iban cambiando debido al crecimiento del bilingüismo en ambos lados de la frontera interlingüística.

Estos cambios contradictorios permitían prescindir de los servicios de los intérpretes oficiales, pero sin que los idiomas andinos desapareciesen. Entonces, ¿quiénes ahora traducirían el aimara y el quechua a la lengua española y viceversa? Se trata de sucesivas inflexiones en un largo proceso de transacciones interlingüísticas que aún son poco conocidas. Es preciso examinar las nuevas relaciones entre los idiomas, no tanto desde la perspectiva de un oficio temprano-colonial (el intérprete), sino a partir de las nuevas capas bilingües — criollas, mestizas e indígenas - que se expandían en los Andes durante la Colonia tardía y la República, aunque no todas al mismo tiempo ni con las mismas consecuencias para la formación de una «literacidad» rural $^{1}$.

En el presente trabajo, examinaré este proceso etnohistórico y sociolingüístico en una conocida área rural del norte de Potosí: el ayllu Macha, de las provincias Chayanta Colquechaca y Charcas $^{2}$, con una ampliación en el tercer apartado

Sobre el concepto «literacidad», ver la antología compilada por Zavala, Niño-Murcia y Ames (2004). Para la experiencia histórica de la escritura alfabética entre las sociedades rurales andinas desde el siglo XVI, ver Salomon y Niño-Murcia (2011), Cummins y Rappaport (2012) y de la Puente Luna (2016).

2 La provincia colonial de Chayanta es conocida en la historia andina sobre todo por la rebelión conducida por los hermanos Katari de Macha Majasaya (ayllu Majapicha) en 1780-1781 (Serulnikov, 2006, 2012). Durante el siglo XIX, la provincia conservaba su capital en el pueblo 
hacia el Altiplano Norte. Con fines comparativos, me concentraré en tres situaciones bien documentadas: la primera corresponde a principios de la República, y las otras dos al siglo XX, antes de la Revolución de 1952. Cada situación se construyó a partir de relaciones diferentes entre los campesinos tributarios y sus autoridades «naturales», la población criollo-mestiza de los pueblos con los jueces y las autoridades nacionales, y los ciudadanos letrados de pueblo y ciudad. Veremos que el dominio de más de un idioma y de la escritura representaba la combinación esencial para la formación de escribanos bilingües, cuyo papel llegó a ser imprescindible para la administración y la justicia regionales.

En conclusión, veremos someramente la secuela política y social del proceso postrevolucionario en Macha Alasaya, y los efectos de la sindicalización en manos de dirigentes bilingües sobre la sociedad de los ayllus.

He aquí las tres situaciones:

\section{El Código de Procederes Santa Cruz (1832)}

Después de la independencia de Bolivia, en 1825, se reafirmó la dominación del español escrito, considerado por una pequeña minoría como la vía necesaria hacia la civilización y la ciudadanía. En el área rural andina, los jueces de Paz cantonales eran ciudadanos bilingües y redactaban sus actas en español, dejando constancia de los «juicios verbales» (orales) que llevaban, en aimara o en quechua, en los pueblos y en el campo. En las capitales de provincia, los jueces de Letras prescindían también de los servicios de intérpretes durante el proceso de

colonial de Espíritu Santo de Chayanta (fundado ca. 1570). Este pueblo dejó de funcionar como capital provincial en 1908, con la formación de la nueva provincia Bustillos en torno a los centros mineros de Llallagua y Siglo XX, con capital en Uncía. Entonces, el pueblo de Chayanta quedaba marginado bajo la jurisdicción de Uncía, pero la capitalía de la provincia recortada de Chayanta, donde seguían los antiguos pueblos de reducción de Macha, Pocoata, Caracara, Moromoro y otros pasó a situarse en el antiguo centro minero de Colquechaca (ver mapa). Esta provincia reducida de Chayanta, dependiente ahora de Colquechaca, se llamaba a veces «provincia Chayanta Colquechaca» para distinguirla de la antigua provincia de Chayanta, cuya cabecera estuvo en el pueblo de Chayanta. Pero ya en 1882, durante el gobierno de Narciso Campero, los valles de los ayllus de la antigua provincia se habían separado administrativamente de sus tierras en la puna, siendo asignados a una nueva provincia Charcas, con capital en San Pedro de Buena Vista. Entonces, los restos de la antigua provincia Chayanta a veces se llamaban «provincia Chayanta Charcas Colquechaca», para indicar la extensión de los ayllus de Chayanta Colquechaca en la puna hasta los valles de la provincia Charcas. Para algunas consecuencias de este reordenamiento, tan negativo a lo largo para los ayllus norpotosinos, ver Platt y Molina (2018) (Estudio introductorio, Cap. I). 
interrogación, y aun de los escribanos, en cuanto redactaban sus propias actas en español. En esto se apoyaban en la nueva legislación republicana ${ }^{3}$.

El Código de Procederes introdujo un conjunto de normativas al proceso legal -no todas nuevas - que fueron aplicadas inmediatamente en la provincia de Chayanta. Ya en 1834-1836 lo encontramos citado y utilizado durante un juicio sobre despojo de tierras entre las dos parcialidades de Macha (Alasaya y Majasaya, «de arriba» $\mathrm{y}$ «de abajo»), por entonces aimarahablantes. Los de Majasaya nombraron a un apoderado (él mismo analfabeto) ante el juez de Paz en el pueblo de Macha, y el apoderado llevó su poder, escrito por el juez de Paz al juez de Letras de la provincia en el pueblo capital de Chayanta, donde presentó otro escrito firmado «a ruego del presentante» por un testigo. El juez de Letras devolvió el caso al juez de Paz del Cantón Macha para ser sentenciado «en juicio verbal» sobre el terreno. Conforme al Código, no estaba presente ningún intérprete con el juez de $\mathrm{Paz}^{4}$, porque este, siendo bilingüe, se encargaba él mismo de los interrogatorios en aimara cuando se reunía con las partes en su despacho o en el campo. Después, redactó las actas en español, prescindiendo también de la ayuda de un escribano.

\section{El curaca recaudador de Macha Alasaya Agustín Carbajal (1900-1985)}

La situación que se impuso a partir de los años 1830, cuando las parcialidades empezaron a ser gobernadas por recaudadores ciudadanos en lugar de curacas indígenas de sangre, no condujo a la hispanización de los ayllus de Macha, menos aún después de la Guerra Federal de 1899, cuando los ayllus retomaron los curacazgos durante casi todo el siglo XX. Al mismo tiempo, el idioma nativo de Macha iba cambiando desde el aimara, pero no al castellano, sino al quechua.

Fue entonces cuando surgieron curacas recaudadores quechuahablantes, quienes, sin saber castellano ni saber escribir, pero con el apoyo de escribanos, letrados y «secretarios» bilingües en castellano y quechua, desplegaron sus saberes y experiencia para administrar la parcialidad de Macha Alasaya, consistente en

Los Códigos Civil, Criminal y de Procederes de Santa Cruz, publicados e introducidos entre 1830 y 1832, tenían la influencia de los códigos napoleónicos y de la Constitución de Cádiz (Barragán, 1999), pero el Código de Procederes siguió al principio a Cádiz sin excluir elementos de la antigua ley castellana (Urcullo, 2015), como las firmas «a ruego de», con testigos, tan importantes en la administración de la justicia entre los analfabetos de la provincia Chayanta.

4 Código de Procederes Santa Cruz, artículo 13: «Jueces de Paz son los que entienden en conciliaciones, demandas verbales y algunas dilijencias judiciales designadas por este código».

5 Para el juicio sobre despojo de terrenos entre las dos parcialidades de Macha, ver Archivo Histórico de Potosí, Prefectura Departamental Expedientes XXXVI (1834). 
cinco ayllus, 25 cabildos, y 5000 a 6000 almas en puna y valles, formando en el proceso un archivo de unos 740 documentos escritos en diversos registros de español ${ }^{6}$. Así podían organizar la recolección de la contribución territorial, o tasa, entre todos los tributarios de su parcialidad, con el apoyo de 75 autoridades cada año (veinticinco alcaldes anuales y cincuenta cobradores semestrales), todos «de turno forzoso» y procedentes de los cabildos de los ayllus. Después, el curaca entregaría el dinero al Tesoro departamental de Potosí7.

El curaca recaudador de Macha Alasaya entre 1937 y 1981, don Agustín Carbajal, tal como lo conocí personalmente y a través de su archivo, era un hombre respetado por muchos contemporáneos ${ }^{8}$. Su fama e influencia se extendían en la región, el departamento, y hasta en La Paz; muchas autoridades criollo-mestizas hablaban bien de él y lo respetaban. Sus métodos de administración pueden compararse con los de un ministro en su despacho; de hecho, don Agustín llamaba su lugar de trabajo «la Recaudación». Aquí oía lecturas de cartas recibidas en castellano y traducidas al quechua por su «secretario», escribano o amanuense bilingüe. Estas traducciones le permitían recibir y analizar correspondencia e informes según criterios lingüístico-conceptuales quechuas, antes de dar sus respuestas, también en quechua, que eran convertidas al castellano notarial por el amanuense.

\section{Los pasquines de los alcaldes mayores (1936-1946)}

La correspondencia en castellano a través de escribanos bilingües representa una forma indirecta de «literacidad rural», sin que se tratase de un escribir indígena propiamente dicho debido a la intervención de escribanos mestizos. Pero entre los años 1936 y 1946, se depositaron en el archivo del curaca de Macha Alasaya ciertos documentos compuestos y escritos por indios de $\mathrm{La}$ Paz en un registro inventado del español, derivado en parte de su lectura de

6 El Archivo del Curacazgo de Macha Alasaya se publica, con imágenes escaneadas, catálogo, índices y un estudio introductorio, en Platt y Molina (2018). Los documentos originales se han quedado en la estancia del curaca, en Liconi Pampa, Macha.

7 La persistencia de la contribución o tasa hasta fines del siglo XX y principios del siglo XXI es un fenómeno propiamente boliviano: en Ecuador y el Perú el tributo se abolió formalmente en los años 1850. Así fue posible que, en Bolivia, algunos curacas y segundas personas retomaran la recaudación a principios del siglo XX, defendiéndola durante casi todo el siglo.

8 Agradezco a Andrés Guerrero, Mark Thurner y Rossana Barragán sus comentarios sobre una versión previa del presente trabajo, y el apoyo del Proyecto Comparativo de la Universidad de Lleida sobre las comunidades rurales de Ecuador y Bolivia, dirigido por Víctor Breton. 
documentos coloniales ${ }^{9}$. Estos textos, que llamaré pasquines ${ }^{10}$, eran creaciones literarias, históricas y políticas, fruto de los intentos de ciertos aimarahablantes del Altiplano Norte por inventar una herramienta de expresión en un castellano propio, como si fuera para romper el dominio del castellano «recibido» u «oficial». Representan una forma de literacidad cuyo significado va más allá que las palabras escritas e incluyen el performance de distribuir las palabras en la página, además del transporte, la distribución y la entrega posterior a las autoridades indígenas y a sus archivos.

Los pasquines son escritos en un español tosco y lapidario, forjado por un movimiento indígena procedente de las orillas del lago Titicaca: los alcaldes mayores ${ }^{11}$. Estos reclamaban la escritura alfabética en castellano como recurso propio, defendían la religión y la ritualidad andinas contemporáneas, e incluso llegaron a criticar el énfasis puesto sobre los documentos antiguos de posesión territorial por los caciques apoderados ${ }^{12}$. Junto con otros grupos, fundaban escuelas particulares en y alrededor de La Paz, y se oponían al servicio militar obligatorio. Sus pasquines expresaban sus reclamos en un español reinventado que, a primer sonido, parecerá una algarabía a los hablantes nativos del castellano. Fueron distribuidos por una red de contactos armada por los alcaldes mayores durante los años 1930 y 1940 y tres llegaron al archivo del curaca de Macha Alasaya, en la provincia de Chayanta Charcas Colquechaca, Potosí1 ${ }^{13}$.

El florecimiento de la escritura en varios registros del español, algunos recogidos en sus archivos por las autoridades indígenas, no es más que una expresión de las complejas situaciones y respuestas que se producen en un contexto de colonialismo lingüístico, considerado como una forma de diglosia

9 Para esta clase de escritura ver, para el Perú, Glave (1990) y Salomon (2002). Para Bolivia, ver Mamani Condori (1991) y Ari (2014).

10 La palabra aimara para «pasquines» en el siglo XX era sirkularanaka (derivación del español circulares). Ver entrevista en aimara con Plácido Jacinto, escribano de Mateo Alfaro, publicada con traducción en Rivera Cusicanqui (1991, pp. 620-621). Las «circulares» se colocan en el tercer grado de autoridad después de los «originales» y las «copias». En la clasificación etnonotarial aimara, el texto publicado abajo se autodenomina certificado; pero por su circulación extendida en múltiples copias y su objetivo político, pienso que «pasquín» es el término más adecuado para designar este género de escrito. Para el uso de pasquines revolucionarios entre los indios del sur del Perú durante las Guerras de la Independencia, ver Glave (2008).

11 Para un estudio de este movimiento aún poco conocido, ver Ari y Chachaki (2008-2010) y Ari (2014).

12 Para el cacique apoderado de Pacajes y la República, Santos Marka Tola, ver el Taller de Historia Oral Andina (1984), Rivera Cusicanqui (1991) y, más recientemente, Gotkowitz (2007).

13 Platt y Molina (2018), Catálogo, C12-3.1, C12-3.2, C12-15. 
(Fishman, 1967; Gumperz, 1982). Tales situaciones muestran las reacciones de una población de habla aimara, primero, y quechua después, frente a la imposición discriminatoria de la escritura en español, considerada como una precondición para la ciudadanía boliviana hasta la Revolución de 1952. Propongo examinar las relaciones entre diglosia, bilingüismo y escritura en el contexto boliviano, comparando en mayor detalle las tres «situaciones» que se acaban de indicar ${ }^{14}$.

\section{DIGLOSIA, BILINGÜISMO Y ESCRITURA EN CHAYANTA, 1834-1836}

La transición a la República boliviana significaba muchos cambios con raíces en la Colonia tardía, entre ellos la abolición de los títulos hereditarios por Simón Bolívar en 1825, confirmada en 1833 por el presidente Andrés de Santa Cruz. Algunos curacas indígenas habían persistido en los Andes desde antes de la Guerra de la Independencia, entre ellos los pirapis de Macha Alasaya, pero fueron reemplazados a principios de la República por nuevos recaudadores bilingües, nombrados entre las élites ciudadanas ${ }^{15}$.

En algunos contextos (por ejemplo, frente a la ley), se estableció una alianza de conveniencia entre los nuevos ciudadanos-recaudadores y sus respectivas parcialidades indígenas, como veremos. Pero pronto los recaudadores empezaban a portarse como mini hacendados, tomando control de los «comunes» de las parcialidades, que cultivaban durante su turno en el cargo con el trabajo de los indios «originarios», y con la semilla puesta por los tributarios «agregados» (Platt, 1991[1984]) ${ }^{16}$.

El gobierno hizo algunos esfuerzos por corregir la situación, intentando (en vano) vender los comunes y reinstalar a los curacas indígenas en los años $1840^{17}$, e incluso separando la colección del tributo de la gobernación de la provincia mediante el establecimiento de colecturías entre 1855 y 1861 (presidencias de Córdoba y

14 Para un dossier sobre el tema del bilingüismo boliviano a fines del siglo XX en sociedades diglósicas (especialmente en las escuelas de Bolivia), ver Plaza (1994); López (1994), y otros participantes en el Seminario Educación Bilingüe e Intercultural, celebrado en el Museo Nacional de Etnología y Folklore (La Paz, 1994).

15 Para la identidad social de los recaudadores norpotosinos en el siglo XIX, ver Platt (1987, pp. 288-289). Se trata de la élite política y económica de la provincia.

16 Para un antecedente relevante en Jesús de Machaca colonial, cf. Rivera Cusicanqui (1978). Aquí se contrastan dos curacas aimarahablantes: uno que administra los comunes para suplir el pago de los tributos, el otro que convierte los comunes en su propia hacienda.

17 Archivo Nacional de Bolivia, Prefecturas Potosí Recibidas, tomo 96, № 21 (1844). Archivo Histórico de Potosí, Prefectura Departamental Expedientes (1902[1842]). Cf. Platt (2009). 


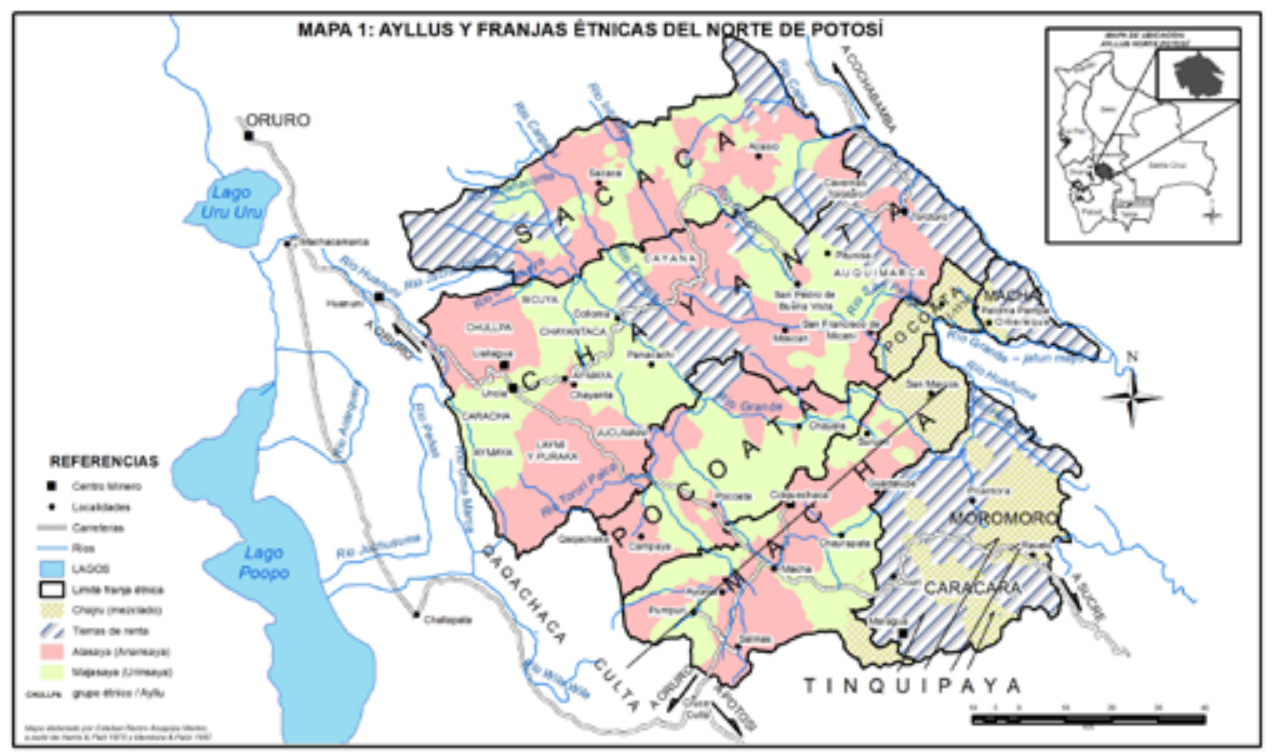

Linares). Pero la presión sobre los ayllus por las élites criollo-mestizas regionales, aún ansiosas de disfrutar de los servicios personales de los indios, persistiría hasta la Guerra Federal de 1899. Tampoco esta presión terminaría en 1902, aunque entonces los ayllus de Macha rechazaron la última revisita, retomando y reteniendo los curacazgos hasta fines del siglo XX (Platt, 2016 [1982]; Platt y Molina, 2018).

A principios de la República, ya eran bilingües muchas autoridades criollomestizas en la provincia de Chayanta, tanto los nuevos recaudadores como los jueces de Paz y de Letras, además de muchos pequeños agricultores, mineros y comerciantes ${ }^{18}$. También hubo algunos campesinos que desarrollaban registros andinos del español, diferentes de los registros de los mestizos. Así se aumentaba la diversidad lingüística que se prestaba para reconocer y manejar diferencias sociales a través de la técnica del «code-switching» (cambios de lengua y/o registro en un contexto bi o multilingüe), tal como ha sido analizada en diferentes partes del mundo por John Gumperz (1982) y otros sociolingüistas (GardnerChloros, 1995).

Pero, por encima de las variaciones de dialecto y registro, persistía el contexto determinante de la diglosia colonial, o sea, la convivencia de dos idiomas

18 En Chayanta los «hacendados» eran pocos, por lo menos en la puna, aparte de los Recaudadores criollo-mestizos y los dueños de los ingenios de beneficio. 
(o grupos de idiomas, dialectos o registros), de los cuales uno ocupaba una posición socialmente privilegiada con respecto al otro. En Bolivia, el español seguía ocupando una posición dominante en los idiomas andinos. Se trata de la primera de las cuatro permutaciones distinguidas por Joshua Fishman (2002[1967]), o sea, diglosia junto con bilingüismo, este último en las fronteras interlingüísticas. Donde hacía falta el bilingüismo, pero subsistía el contraste diglósico, encontramos una segunda situación, o sea, diglosia sin bilingüismo más allá del mismo intérprete, tal como se daba en los primeros años de la dominación colonial ${ }^{19}$.

La posición dominante del español fue reforzada, como ya se ha visto, en cuanto la capacidad de escribir en español se concebía por los gobernantes criollos como el camino necesario hacia la ciudadanía y la «civilización», un camino cerrado a la mayoría aimara o quechuahablante del país, predominantemente analfabeto y con poco o ningún conocimiento del español ${ }^{20}$. Por otra parte, el español era el medio de comunicación escrita entre todos los ciudadanos que trabajaban como funcionarios del estado en la frontera lingüística. Sin embargo, veremos que el Código de Procederes Santa Cruz presuponía el probable conocimiento por los jueces de por lo menos un idioma andino. En estas circunstancias era posible prescindir de los intérpretes calificados, y ahorrar sus salarios ${ }^{21}$.

Veamos, primero, el caso de los intérpretes de visita, que tenían una función importante durante la Colonia, ayudando a actualizar la relación cambiante entre la población, la tenencia de la tierra y la distribución de los tributos. Pero con la Independencia, los intérpretes de visita empezaron a desaparecer. Todavía en octubre de 1829 el gobernador de Chayanta, J. M. González, lamentaba la demora de la revisita que había empezado en abril, atribuyéndola ${ }^{22}$ a la falta de caciques propietarios (ya abolidos por los decretos de Bolívar), lo que significaba que la recaudación de los tributos se encargaba a «cobradores provicionales [sic] a quienes les faltaba informarse sobre sus responsabilidades en sus parcialidades».

19 Debe observarse que la jerarquía de los idiomas no es inmutable, sino contextual, y que en ciertos contextos el español «cerrado» puede provocar también una respuesta equivalente entre los quechua- o aymara-hablantes.

20 En los años 1830 se intentaba introducir escuelas rurales en el departamento de Potosí para aumentar la enseñanza del español, y así crear rápidamente las precondiciones para la ciudadanización entre los quechua y aimarahablantes. Tuvo un efecto limitado en el área rural, aunque puede haber fortalecido el uso del quechuañol en los pueblos mestizos. Ver Platt (2009).

21 En la Colonia también hubo indígenas bilingües a quienes se dio la opción de tener intérpretes para controlar mejor el proceso de la traducción (ver Cunill, en Cunill y Glave Testino, 2018).

22 Otras causas eran (i) el «doble domicilio de los yndigenas en puna y valle, no pudiendo reunirlos por estas circunstancias en los días señalados», y (ii) las disputas sobre los terrenos. 
En consecuencia, el gobernador tuvo que «entenderse solamente con los ylacatas y principales [autoridades al nivel del ayllu y cabildo] a quienes no es fasil comprenderles, a pesar de los ynterpretes, porque siempre proceden con malisia ...» [énfasis mío]. Aquí los intérpretes aparecen como muletillas débiles porque, con la abolición de los curacas hereditarios, no era fácil comprender los testimonios en aimara que circulaban en los niveles locales de la sociedad rural ${ }^{23}$.

Las revisitas eran operaciones burocráticas que debían repetirse cada cinco años en cada provincia (en la práctica eran menos frecuentes) para establecer el número de los tributarios, redistribuir algunas tierras, y fijar el monto de dinero para cada tributario, ayllu y parcialidad. Los intérpretes de visita se consideraban esenciales en Chayanta hasta 1843. Sin embargo, en enero de 1843 el entonces revisitador de Chayanta escribió al ministro de Hacienda para decir que había cumplido con un Supremo Circular aboliendo el puesto de «intérprete de revisita». Su carta nos ofrece un cuadro de la situación lingüística en Chayanta, con las dificultades que significaba la pérdida del intérprete:

es savido SM que en esta Provincia no se ha profesado otro idioma que el aimara, y no entendiendo el Gobernador Juez de Vicita Ciudadano Mateo sino la quechua, y yo desgraciadamente ni uno ni otro como es constante, nos hallamos en la oscuridad de no poder empadronar a indios absolutamente cerrados al aimara. Por semejante imposivilidad, ruego a VG se sirva someter al conocimiento de SE el Jefe de la Nación [...] y para solo concluir dos cantones que faltan, se digne consederme la procecucion del intérprete que ha desempeñado con ecsactitud la mayor parte de la Provincia; en atencion a que el haber que se ahorraría con la supresión de este empleado, es demaciado pequeño que no merece la pena, cuando ya está imbertido la mayor parte ${ }^{24}$.

Este testimonio sobre la suspensión del intérprete (con el fin de ahorrar su salario) también confirma que, en Macha, como en todo el resto de Chayanta,

23 Archivo Histórico de Potosí, Prefectura Departamental 78, no 80. En Chayanta, hubo ayllus grandes (Macha, Pocoata, Chayanta, Sacaca, etc., ver mapa), a menudo divididos en parcialidades cada una encabezada por un curaca recaudador, y subdivididos en ayllus menores. En Macha, cada parcialidad se subdividía en cinco ayllus menores encabezados por cinco Ylancos, y (en el caso de Alasaya) subdivididos a su vez en 25 cabildos territoriales, cada uno con su alcalde o Ylacata anual. En el siglo XX cada cabildo también tenía un cobrador semestral. Todos eran cargos de «turno forzoso» dependientes del cabildo y del curaca. Ver Platt y Molina 2018 (Cap. I).

24 Archivo Nacional de Bolivia (Sucre), Ministerio de Hacienda, Prefecturas Potosí Recibidas t.93 no 34 (Pitantora, 2 de enero de 1843). Se nota que la abolición de los intérpretes respondía, por lo menos en parte, al deseo de economizar en los gastos de la revisita. Para los exorbitantes gastos que acarreaban los intérpretes coloniales, y los riesgos de corrupción, ver Jurado (2010, p. 303). En 1843, aparentemente, se hablaba el aimara tanto en Pitantora (hoy quechuahablante) como en el resto de la provincia. 
se hablaba aimara a mediados del siglo XIX. Solo en la segunda mitad del siglo Macha iba a cambiar del aimara al quechua, debido al influjo de migrantes quechuahablantes hacia el centro minero de Colquechaca, y la expansión de la hacienda desde Chuquisaca en las fronteras meridionales del ayllu Macha. Así se creaba, en algunas regiones, una situación trilingüe (aimara, quechua y castellano) que persiste hasta hoy. Pero en Macha se producía una nueva situación diglósica entre el castellano y el quechua, con un nuevo bilingüismo presente en la frontera sociolingüística.

Otro contexto donde antes se recurría a los intérpretes era en los juicios, donde se interrogaba a testigos aimara o quechuahablantes mediante traductores (ver Glave Testino, en Cunill y Glave Testino, 2018). En la República se reconocía que el bilingüismo había obviado la necesidad de recurrir a intérpretes en las cortes. Como decía el artículo 312 del Código de Procederes Santa Cruz:

Cuando se examinen testigos por intérpretes, se nombrarán dos que jurarán lo mismo que el testigo, a no ser que las partes convengan en uno, o no haya otro en el lugar. No se examinarán testigos por intérpretes, sino cuando el juez y el escribano ignoren el idioma del testigo [énfasis mío].

La última frase de este artículo - el único entre los 1534 artículos del Código que trata de los intérpretes - nos aclara por qué no se encuentra ni una sola mención de intérpretes en el pleito sobre terrenos entre las dos parcialidades de Macha. Aquí, la traducción de las palabras del «actor»y del «demandado» (para adoptar los términos del Código) estuvo en manos del juez de Paz del cantón Macha, con la participación ocasional de los recaudadores ciudadanos, además de los testigos. En este juicio, las actas y los testimonios escritos se basaban en la interrogación oral de testigos «cerrados» al aimara, seguida por la recepción de los testimonios en aimara y su traducción silenciosa («en su cabeza») por el juez bilingüe y letrado. Finalmente, después de elegir equivalencias semánticas en silencio, el juez se encargó de escribir las actas y sentencias en español. Lo mismo hacía el juez de Letras en Chayanta si faltaba el escribano público de la provincia.

Recalcamos que, si bien el juez de Paz sabía traducir los testimonios en aimara al castellano sin un intérprete oficial, igualmente - como ciudadano letradopudo escribir las actas del expediente en español sin un escribano. A diferencia de los intérpretes, el Código de Procederes de 1832 dedica toda una sección a los escribanos (artículos 123-145). Pero en el expediente de 1834-36 solo se menciona al escribano público adscrito a la Corte de la capital provincial de Chayanta. Este funcionario, antes de asumir su cargo, tenía que presentar su título, emitido por 
el gobierno, al juez de Letras. Pero solo raras veces se le menciona para sentar alguna acta del juez de Letras, sin inmiscuirse en la redacción de las actas del juez de Paz de Macha, quien se encargaba de su propia escritura.

El Código Santa Cruz está presente en todo el juicio de 1834-1836, poniendo en marcha o confirmando procedimientos que contribuirían a determinar la práctica legal republicana. Aquí nos interesa particularmente el artículo 129, que establece que los escritos presentados por «personas que no sepan firmar» solo serán aceptadas en caso que «aseguran estar firmados a su ruego, lo que sentarán por diligencia» [énfasis mío]. Este artículo (que recupera antiguas prácticas coloniales y peninsulares) subyace en los miles de documentos emitidos más tarde en nombre de indígenas que «no firman por no saber» (cf. artículo 131), documentos que debían ser firmados por letrados y escribanos «al ruego» del presentante y (en lo posible) en presencia de testigos ${ }^{25}$.

Veamos quiénes participaban en la traducción y la escritura durante la administración de justicia en Macha a principios de la República. El pleito empezaba cuando, en marzo de 1834, algunos indígenas de la parcialidad Alasaya de Macha (ayllu Alacollana) barbecharon terrenos que los campesinos de Majasaya (ayllu Majacollana) reclamaban como suyos, siendo también pastos para su ganado. Los Majasayas pidieron ayuda al juez de Paz de Macha, ciudadano Felipe Vásquez, sin darse cuenta de que Vásquez iba a asumir el puesto de recaudador de los Alasayas y, por tanto, ya era «interesado de la contraparte». Felipe Vásquez aconsejó a los majasayas, disimulando, que esperasen hasta agosto de 1834, cuando los alasayas volverían de los valles, a los que se desplazaban anualmente para la cosecha del maíz, y entonces él arreglaría la situación sin que fuese necesario acudir al juzgado. Los majasayas esperaron hasta agosto, pero no pasó nada, y siguieron esperando hasta octubre de 1834 — cuando de golpe los alasayas, ya de vuelta de los valles, volvieron «a sembrar con mucha biolencia respecto a que el nominado Basquez es ya Recaudador de los contrarios» ${ }^{26}$.

Dándose cuenta de su error, los majasayas nombraron como su apoderado a Mariano Senteno (quizás descendiente de sangre de Blas Senteno, cacique indígena de Majasaya en 1761 según nota adjunta al juicio). Su Poder es el primer documento del expediente. Senteno era analfabeto y no sabía firmar, pero llevó

25 Se añade, a veces, la impresión digital del analfabeto al lado de su nombre escrito por el letrado o escribano.

26 La invasión afectaba una frontera notoriamente sensible: Cuymuri Collo («cerro de Cuymuri»), cerca del salar de Carata en lo que antes era el Cabildo Carata, hoy llamado Cabildo Cuymuri. Para los antecedentes de esta disputa ver Platt (2018b [en prensa]). 
el Poder al pueblo capital de Chayanta para pedir justicia del juez de Letras, entablando un juicio de despojo contra los alasayas. El 6 de diciembre de 1834 el juez de Letras decretó — proveyendo y firmando «ante un testigo por audiencia del escribano que certifico»— que se prosiguiera la conciliación por el juez de Paz de $\mathrm{Macha}^{27}$. El juicio se postergó hasta el día 29. Entonces los alasayas presentaron un «documento fe haciente, que delinea a ambas parcialidades de Alacollana y Majacollana practicadas por el Visitador y medidor de tierras don Santos Garcia de la Vandera el año de 1745, mas no se ha podido esclarecer en que parte se hallan los terrenos en disputa». Ambas partes, «actor y demandado», exigieron «se haga vista de ojos con arreglo a los documentos». El juez de Paz firmó «con los testigos de mi actuación, y porque las partes no supieron, firmaron otros a su ruego, de que sertifico».

E1 9 de enero de 1835, el juez de Letras, Manuel Díaz de Pareja, decretó que «venga con arreglo al artículo 641 del Código de Procederes, deviendo además espresar el ocurrente los nombres de los terrenos que hubiesen sido despojados últimamente sin confundir con los que sirvieron de objeto al anterior despojo...» (de hecho, el primer despojo era el barbecho, y el segundo la siembra de las mismas tierras). En esta ocasión, el apoderado Senteno recibió una Notificación escrita por parte de Diego Valda, escribano público de la corte en Chayanta.

En su respuesta, Senteno nombró los terrenos - Cuimuri Collo, Ananoca y Tucani Jiquina-, y «por último deseando acreditar en toda forma el despojo advitrario y violento, y tener nesesidad de calificar los dos estremos eyección y posesión anticuada», pidió al juez que recibiera información de testigos ante el juez de Paz de Macha, con previa citación de los contrarios.

Entonces la escena volvió de nuevo al Cantón Macha, donde el 19 de enero de 1835 un nuevo juez de Paz, Lorenzo Bernal, acusó recibo de la comisión enviada desde Chayanta por el juez de Letras. Luego se interpuso un intervalo de nueve meses hasta que, el 20 de octubre, recién aparecieron el apoderado de los Majacollanas Mariano Senteno con los demandados del Ayllu Alacollana, «menos el Alcalde del Ayllu Carlos Sirapo por residir en los valles». Obviamente, el intervalo se debe a que la mayoría de los campesinos se había ausentado a los valles, de donde solo volverían para el mes de octubre. Ninguno de los presentes sabía firmar, y lo hizo por ellos, y «a su ruego», uno de los testigos.

27 Cf. Código de Procederes Santa Cruz, artículo 13. La conciliación era una etapa previa antes de proceder al juicio verbal. 
Luego se interrogó a tres testigos en el despacho del juez de Paz, todos en favor de los majacollanas. El primero era un indígena originario del ayllu Majacollana de ochenta años «que no es sirbiente ni doméstico ni pariente de ninguna de las partes». El segundo era un «comerciante criollo blanco del domicilio de este Canton, con vecindad en la Ciudad de Chuquisaca, que no es sirviente ni doméstico ni pariente de alguna de las partes», aunque había sido recaudador de la parcialidad de Majasaya. Se nota otra vez el apoyo legal proporcionado a su parcialidad por el recaudador ciudadano. El tercero era un mestizo, de oficio músico y empleado en el coro de la iglesia de Macha, de sesenta años. El primer testigo seguramente habló en aimara, los otros dos en castellano. Todos confirmaron la legítima posesión de las tierras por los «actores» de Majacollana.

El 19 de diciembre, el juez de Paz aceptó la comisión del juez de Letras de Chayanta y ordenó las citaciones de las partes «en el mismo puesto de los terrenos de la contienda». En seguida, dijo al apoderado Mariano Senteno que se presentase en el lugar de los hechos el 3 de enero de 1836.

Llegado a los puntos de Tocani Yquina, Cuymuri Collo y Ananoca, el juez convocó a los indígenas de Alacollana, citándoles al tenor del auto (y «no firmaron por no saber»). Luego, ambas partes fueron ordenadas a exponer sus razones, «de las que se tomó un prudente balance». Finalmente, se declararon los terrenos propiedad de los comunarios de Majacollana, se les dio la posesión formal, «y para constancia firmé con los testigos de mi actuación por los presentes, porque expresaron no saber, de que certifico». Los papeles originales fueron devueltos a Senteno «para los usos que bien le convenga».

Si observamos esta secuencia de actos de habla, escritura y desplazamiento, muchos estipulados por el Código Santa Cruz, podemos notar la total ausencia de cualquier mención del otro idioma presente, el aimara, cuya existencia es sistemáticamente invisibilizada ${ }^{28}$. El único idioma que el texto reconoce es el español, idioma vinculado legalmente con la ciudadanía. Pero es indudable que todos los campesinos, tanto actores como demandados, hablaron en aimara. Todos los que se presentaron eran analfabetos, sin hablar nada más que algunas palabras de castellano, y en 1834-36 ningún indígena presente en el pleito supo firmar su nombre. Los testigos criollo-mestizos generalmente firmaban por los testigos indígenas. En la localidad, el juez de Paz de Macha era su propio intérprete y escribano, y lo mismo fue generalmente el caso del juez de Letras en la capital provincial de Chayanta.

28 Para la invisibilización documental mucho más exitosa de los indios en la Argentina del siglo XIX, ver Rodríguez (2016). 
En el juicio verbal realizado en el lugar de Cuimuri Collo, el juez de Paz, bilingüe, habría hablado en aimara con los campesinos del lugar, con o sin testigos, antes de redactar las actas en castellano. Solo en la corte del pueblo capital de Chayanta encontramos a un escribano público; pero el juez de Letras conversaba en aimara con el apoderado Mariano Senteno (quizás con la ayuda de testigos), antes de escribir las actas en castellano.

Según las evidencias, los actores y demandados eran todos «cerrados al aimara», pero los jueces y testigos criollo-mestizos sabían lo suficiente para poder «interpretar» a los indígenas, interrogándoles y traduciendo sus palabras orales en aimara a palabras escritas en castellano. Al final, se escuchaba el aimara en las calles de Macha, junto con el español, desde que se nacía, y los ciudadanos necesitaban saber aimara o quechua para comerciar, además de administrar justicia a los que se situaban al otro lado de la frontera lingüística. Seguramente algunos campesinos sabían palabras del español, aunque no pudiesen firmar. Evidentemente, era perfectamente factible en la República boliviana prescindir de un intérprete profesional, e incluso de un escribano, durante las interrogaciones realizadas en las fronteras lingüísticas del país.

\section{EL ARCHIVO DEL CURACA DE MACHA (ALASAYA)}

Haremos ahora un salto de cien años hacia la primera mitad del siglo XX. Para entonces, la situación lingüística en Macha había cambiado radicalmente. En primer lugar, el quechua reemplazó al aimara como idioma mayoritario desde fines del siglo XIX. Además, en el siglo XX disponemos de una fuente única: los documentos en castellano del archivo de Macha Alasaya acumulado por los curacas recaudadores, y perteneciente desde 1937 a la familia Carbajal. En 19701971 había yo realizado un primer trabajo de campo, de más de un año, en los valles de Macha y en la puna con los Carbajales, y en varias visitas posteriores pude ya ver y publicar algunos documentos (Platt, 2016[1982], Apéndices etc.). Pero no fue posible consultar el archivo en su totalidad hasta el año 2014.

Don Agustín Carbajal (1900-1985) nació justo después de la Guerra Federal (1899), en un momento en que los ayllus retomaban el control de los curacazgos y de la recaudación de la contribución territorial, después de un largo período cuando las parcialidades fueron encabezadas por ciudadanos-recaudadores criollo-mestizos. Agustín era analfabeto y monolingüe en el quechua sureño de Macha (un dialecto influenciado por el aimara y el castellano). Al principio, gobernaba con la ayuda de letrados, «secretarios»y «escribanos de comunidad» 


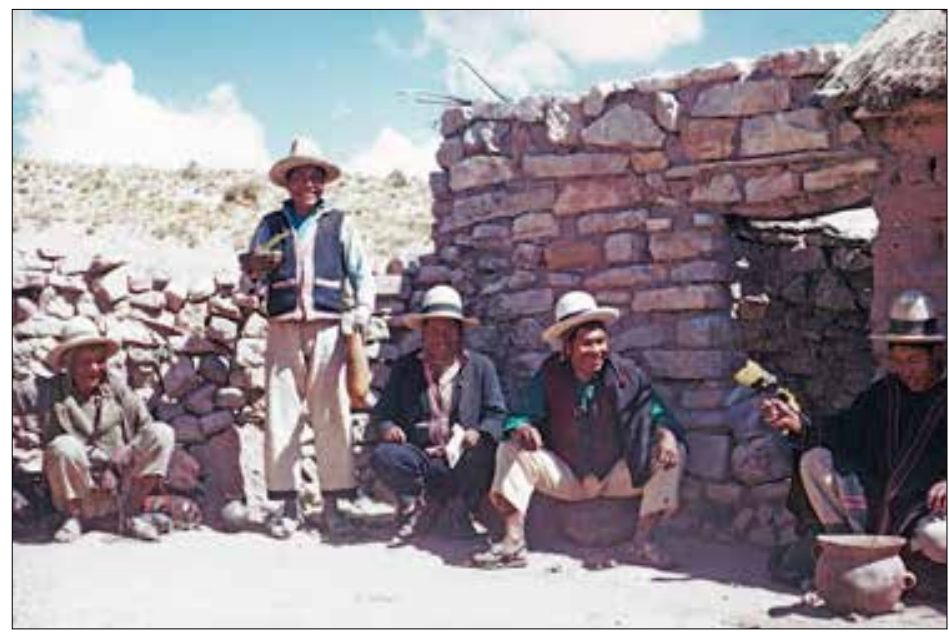

Lámina 1. Miembros del patriclan Carbajal. A la izquierda, de cuclillas con su ch'uspa de coca, el curaca de Macha Alasaya, don Agustín Carbajal, a los setenta años; sentados al centro sus hijos Santiago y Gregorio Carbajal; de pie con turu wasu y tutuma de chicha, Dionisio Carbajal, tercer hijo de Santiago; sentado a la derecha detrás de una olla de chicha, Marcos Carbajal, sobrino de Agustín. Foto: Tristan Platt, Liconi Pampa, 1971.

bilingües, ejerciendo de esta manera lo que llamaré una «literacidad indirecta», porque dirigía pero no ejecutaba la escritura. A partir de 1944, sus hijos Santiago (m. 1977) y Gregorio (1941-2014) empezaron a asumir las tareas del escribano.

Poco después de la Revolución de 1952, Agustín fue marginado por los sindicatos del MNR (Movimiento Nacionalista Revolucionario) desde el segundo semestre de 1954 hasta el segundo semestre de 1961, cuando volvió a gobernar hasta 1981. Pero no perdonó al presidente Víctor Paz Estenssoro su marginación, ni a los dirigentes movimientistas su prepotencia y corrupción: tanto los sindicatos como la misma subprefectura querían apropiarse de la contribución territorial para sus propios usos (Platt y Molina, 2018, cap. IV). En julio de 1971, cuando lo conocí por primera vez, el curaca me mostró algunos documentos selectos de su archivo, entre ellos una denuncia a máquina, realizada en Milluri (Macha) en 1963, contra Paz Estenssoro, el catastro y el «movimientismo traficante» ${ }^{29}$. De ahí su apoyo para el golpe del vicepresidente René Barrientos Ortuño en 1964, y para su candidatura a la Presidencia dos años más tarde, en 1966. Pero don Agustín abandonó a los barrientistas cuando en 1969 (después de la muerte de

29 Ver el «Pronunciamiento Campesino de Macha» (1963), en Platt y Molina (2018, Catálogo, C7-10.) 
Barrientos) el dirigente local, Lino Limachi, empezó nuevamente a secuestrar la contribución territorial que Agustín recaudaba para el Tesoro de Potosí3 ${ }^{30}$.

Los archivos de las comunidades indígenas son un fenómeno poco documentado en Bolivia ${ }^{31}$. El archivo curacal de Macha Alasaya expresa, en primer lugar, la determinación de los curacas por conservar las constancias de su gestión fiscal como encargados de la recaudación para el Tesoro prefectural. También contiene mensajes sobre la administración de justicia y constancias de los servicios desempeñados «por turno forzoso» por los comunarios de su parcialidad, y cartas con varias instancias sobre la recaudación de los dineros del Estado. Todos los pasantes de cargos fiscales debían recibir certificados de su nombramiento y cumplimiento, y finiquitos por los dineros tributarios entregados: una inmensa cantidad de papel escrito por los escribanos del curaca. Varias copias de estos documentos han quedado en el archivo.

Los curacas guardaban todo documento que llegaba a su poder y les parecía importante ${ }^{32}$, junto con copias de algunos documentos remitidos por ellos hacia fuera de la comunidad. Además, el archivo contiene varios documentos sindicales posteriores a 1952, que llegan hasta el año 2000, junto con algunos papeles antiguos correspondientes al siglo XIX, y algunos traslados coloniales. Toda esta documentación se ha incorporado en un archivo de enorme valor para una etnohistoria de Macha y del campesinado norpotosino durante el siglo XX.

Agustín gozaba de gran prestigio por su participación en la Guerra del Chaco (1932-1935) donde fue en 1934-1935, por el cuidado con que recogió y entregó la contribución territorial a partir de 1937 y por la tenacidad con la que defendía a los ayllus ${ }^{33}$ contra los abusos de mosos, corregidores y militares, sobre todo entre 1937 y 1943. Asistió al Congreso Indigenal de 1945 en La Paz, donde se le tomó una foto (que se conserva en el archivo), agarrado de sus papeles y rodeado de otros caciques de Potosí y Chuquisaca (Lám. 2). Gobernaba su parcialidad,

30 Lino Limachi era inspector agrario en Huancarani, Pocoata, en 1953, donde en 1954 se fundaría el Ejército Campesino «Tupac Catari». Después era representante sindical de Barrientos en las elecciones de 1966. Para el secuestro de los fondos de la contribución, y otros aspectos de su vida, ver Platt y Molina (2018, Cap. V).

31 Para el archivo de Santos Marka Tola, ver Rivera Cusicanqui 1991; para los archivos de los alcaldes mayores particulares, ver Ari (2014). Para el archivo de Tupicocha, Perú, ver Salomon 2002; para los archivos prehispánicos de quipos, ver Urton (2017).

32 Entre muchos ejemplos, mencionaré la invitación enviada en 1970 a Agustín Carbajal, y a un representante de Majasaya, por Fausto Reinaga, «escritor indio», para encontrarse con el presidente Gral. Ovando (Platt y Molina, 2018, Catálogo, C12-24).

33 Hubo diez ayllus de Macha con los mismos nombres desde el siglo XVI, cinco en cada parcialidad. Los de Alasaya son: Alacollana, Sullcavi, Huaracata, Tapunata, Alapicha. 


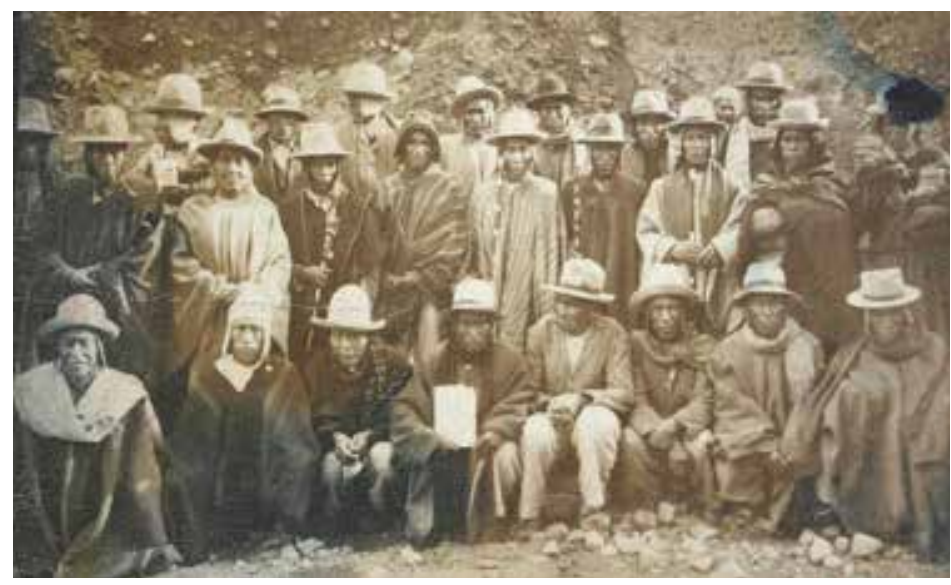

Lámina 2. Don Agustín Carbajal está sentado al centro, agarrado de sus documentos y rodeado por caciques de Potosí y Chuquisaca (1945). Dos mujeres son parte del grupo. Copia conservada en el Archivo del Curacazgo de Macha Alasaya.

emitiendo y recibiendo mensajes en español, durante más de cuarenta años, con la ayuda de letrados y escribanos que traducían, redactaban y firmaban «a su ruego.

Don Agustín murió en 1985, dejando el curacazgo y el archivo al cuidado de su hijo menor Gregorio. Gregorio había aprendido algo de castellano escrito en sus clases de primaria y en sus interacciones con los escribanos bilingües, suficiente como para desarrollar una escritura notarial adecuada, y pudo hablarlo también, aunque con dificultad (ver Platt, 2014) ${ }^{34}$.

Como he mostrado en la introducción a su catálogo (Platt y Molina, 2018), el archivo de Macha Alasaya nos muestra el funcionamiento de la parcialidad Alasaya como una construcción política y administrativa, así como las grietas en la estructura de autoridad, que crecían con los años. Al mismo tiempo, los papeles ofrecen valiosas perspectivas sobre los problemas de traducción y escritura planteados en este ensayo.

En primer lugar, las funciones del intérprete y del escribano terminaron fusionándose en la recaudación de Liconi Pampa. Desde antes de los primeros gobiernos de Agustín (1937-1954), era necesario que la persona que actuara de letrado, escribano o «secretario» del curaca en funciones fuera bilingüe para poder traducir la correspondencia, en voz alta, desde el castellano escrito al quechua

34 La primera escuela de Liconi Pampa fue instalada a petición de Agustín en ca. 1948. Santiago había aprendido a escribir en castellano antes de la llegada de la escuela local. 
hablado, y después capaz de transformar la respuesta desde el quechua del curaca al texto escrito en castellano, firmando «a ruego del» curaca. También el escribano debía escribir y firmar los nombramientos, finiquitos y certificados para todos los que cumplían con los cargos fiscales de «turno forzoso».

En 1971 pude observar cómo el viejo Agustín continuaba atendiendo consultas, tendiendo un tejido sobre un banco de adobe, fuera de su casa, para recibir al visitante, a veces con comida traída por su mujer, sosteniendo conversaciones informales con los que se acercaban trayendo noticias, rumores o buscando sus consejos, además de asistir a las reuniones formales (juntas y cabildos). Guardaba algunos documentos de gran valor entre dos cueros secos de oveja y tenía una idea clara sobre la importancia relativa de los diferentes papeles, aunque no los pudo leer, poniéndoles nombres breves a los más significativos, nombres que resumían su contenido: «Garantía general», «kintali sut’i» [= quintal de azotes], «Pronunciamiento», «Ayoma», etc. ${ }^{35}$.

Es importante notar que los escribanos no parecen haber manipulado el contenido de los mensajes del curaca; de hacerlo, pronto habrían sido detectados, castigados o suspendidos. Traducían el mensaje al quechua y escribían la respuesta en castellano, conversando los datos con el curaca en quechua y aportando la forma notarial y las fórmulas legales para completar la traducción al castellano. El curaca elegía a quien quería, a quien estaba disponible y en quien tenía confianza, pero entre 1926 y 1948 solo hubo un escribano, Pedro Gómez, quien firmó «escribano de comunarios». Veamos los casos de dos escribanos que trabajaban con el curaca.

En el archivo existen varios documentos fechados entre 1926 y 1936 y firmados por el escribano Pedro Gómez «al ruego» del anterior curaca recaudador, Pedro Ramírez. Y desde 1937 hasta 1948, Pedro Gómez también firmaba documentos para Agustín Carbajal. Sus servicios al curacazgo de Macha Alasaya duraron más de veinte años, concentrándose en los años anteriores a 1940.

Existe poca información sobre Pedro Gómez, aparte de la que tienen sus cartas manuscritas. Sabemos que, en 1932, era profesor normalista en Macha, y al principio de la Guerra del Chaco (1932-35) actuó de intermediario entre el corregidor de Macha, Macedonio Villalta, y el cabildo Pichichua (ayllu Alacollana), donde vivían Agustín Carbajal, por entonces alcalde del Cabildo, y el curaca de Alasaya

35 Para los dos primeros documentos, ver Platt y Molina (2018, apéndices 2 y 3). Para el «Pronunciamiento de los Campesinos de Macha» (1963), ver Platt y Molina (2018, cap. IV, lám. 4.5). «Ayoma» fue un documento que pude ver en 1971, pero ahora está perdido. Trataba de los linderos entre los ayllus y un hacienda-ingenio colindante, que fue uno de los ingenios que rodeaban Colquechaca en los siglos XVII-XIX. Hoy, Ayoma es capital de un cantón. 
Pedro Ramírez, a cuatro horas de caminata del pueblo de Macha. A instancias del corregidor, Pedro Ramírez y Agustín Carbajal organizaron, juntos la limpieza de esa parte del camino entre el pueblo de Macha y Cruce Culta que correspondía al Cabildo Pichichua, para facilitar el tránsito de la tropa militar (Platt y Molina, 2018, Catálogo, C14-2), e hicieron entregar costales de papas, chuño y quinoa para el ejército a las Casas de Aprovisionamiento en Colquechaca y Potosí, según documentos escritos y firmados por Pedro Gómez (Platt y Molina, 2018, Catálogo, C14-6).

Después de la Guerra, Pedro Gómez se reunió con el curaca para calcular la Contribución territorial en función de la información proporcionada a Agustín Carbajal por los ylancos y alcaldes (Lám. 3). La recaudación semestral para Navidad de 1937 formaba el punto de partida del proyecto político-fiscal de Agustín, aunque se basaba en la teoría y la práctica de sus antecesores, especialmente de Pedro Ramirez (ver Platt y Molina, 2018, esp. cap. II). Gómez colaboraba, también, junto con otros escribanos y letrados bilingües, para que don Agustín pudiera organizar una campaña escrita en castellano contra los abusos y atropellos de mosos, militares y corregidores en la puna y los valles de Macha. Con este objetivo, el curaca viajaba a los ministerios en La Paz, a la prefectura y los juzgados en Potosí, además de sus visitas al corregidor, a la Policía y a los jueces en el pueblo de Macha, a los valles de San Marcos de Miraflores y Carasi, y a la subprefectura y el juzgado en el centro minero y capital provincial de Colquechaca.

Entre 1926 y 1948, Pedro Gómez firmaba de distintas maneras: «escribano», «escribano de comunarios», «escribano de diligencias», «escriba de los comunarios», «escribano interrogador». Quizás fue su apoyo a las causas indígenas lo que provocó que otro corregidor de Macha, Luis A. Ovando, le escribiera una breve nota en 1938:

Escribano Gómez = El reclamo que hacemos los del pueblo y de la comunidad ante el señor Prefecto ha surtido, tengo orden de buscar a otra persona del pueblo, y oportunamente les comunicaremos quien va ser el designado. Suyo,

Luis A. Ovando.

Macha, 24 de marzo de $1938^{36}$.

Posiblemente, el corregidor se había molestado con las actividades del profesor normalista en favor de los indígenas y quería encontrar un sustituto. Pero diez años después aún encontramos a Pedro Gómez trabajando con Agustín Carbajal y firmando como «escriba de comunarios» (Platt y Molina, 2018, Catálogo, C5-27).

36 Platt y Molina (2018, Catálogo, C12-4). Lamentablemente no está claro quien pagaba a Pedro Gómez, pero esta nota sugiere que su cargo era reconocido por el Corregimiento y por la Prefectura. 


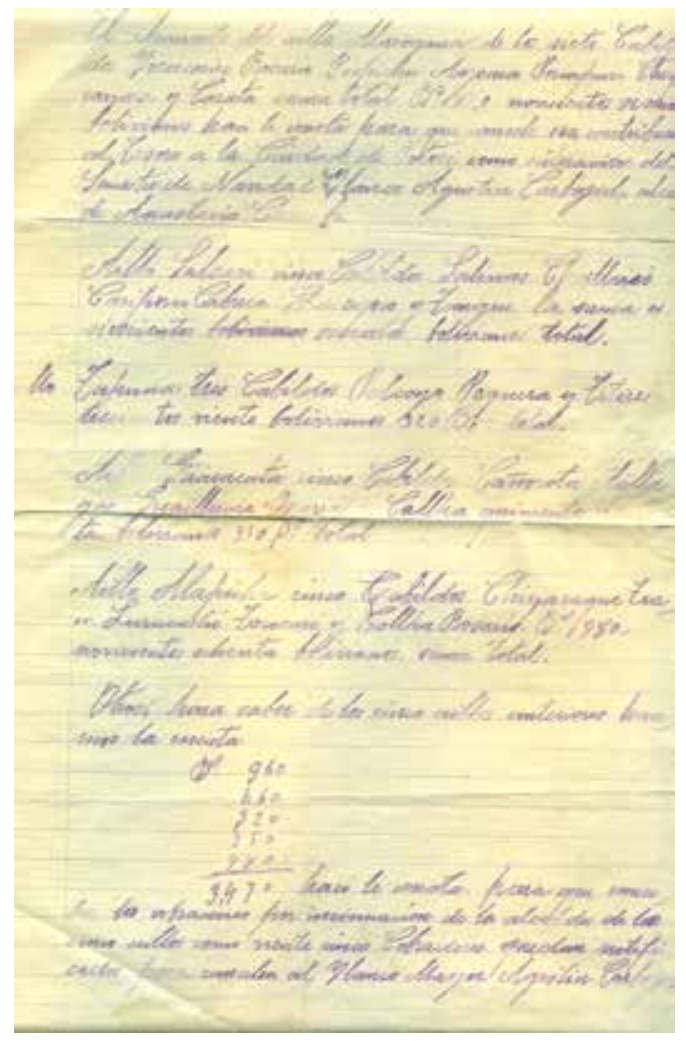

El chancelo del aillo Alacoyana de los siete Cabildos Yoracarire Rosario Pichichua Ayoma Pumpuri Choquecayara y Carata suma total Bs/ 960 novecientos sesenta bolivianos hasi le consta para que cancele esa contribución al Tesoro a la Ciudad de Potosi como enteracion del Semestre de Navidad Ylanco Agustin Carbajal alcalde Anastasio Chambi.

Aillo Sulcavi cinco Cabildos Salinas Challviri Cariporco Cabreca Quiojo y Tanqui la suma de siescientos sesenta bolivianos total

Aillo Tapuna [sic] tres Cabildos Palcoyo Poquera y Titire trecientos bolivianos $320 \mathrm{Bs} /$ total.

Aillo Güaracata cinco Cabildos Cañocota Aullagas Guailloma Oscoria Callpa quinientos cincuenta Bolivianos 550 Bs. Total.

Aillo Alapicha cinco Cabildos Chiyaraque Turco Lurucachi Tococari y Collpa Rosario Bs 980 Novecientos ochenta bolivianos suma total.

Otrosi hara saber de los cinco aillos anteriores hacemos la cuenta Bs.

$$
\begin{aligned}
& 960 \\
& 660 \\
& 320 \\
& 550 \\
& \underline{980} \\
& 3,470 \text { hasi le consta. Para }
\end{aligned}
$$
que cancelen los cobradores por insinuación de los alcaldes de los cinco aillos como viente cinco Cobradores quedan notificados para cancelen al Ylanco Mayor Agustin Carbajal.

Lámina 3. Lista de cinco ayllus con sus cabildos de Macha Alasaya con las sumas tributarias que corresponden a cada ayllu. La escritura es de Pedro Gómez. s/f ca. 1937.

Otro escribano recurrente en este período era Alberto Miranda, quien en 1940 representó a los comunarios de los ayllus y a su curaca recaudador. Estos protestaban contra un moso prepotente del pueblo de Macha, Macedonio Villalta, sin duda el mismo que fue corregidor en 1932. Ahora Villalta intentaba apoderarse del curacazgo de Alasaya (siguiendo los pasos de los recaudadores ciudadanos del siglo XIX). Entonces, Miranda redactó un informe al subprefecto en nombre de tres ayllus y diecisiete cabildos de Macha Alasaya: Alacoyana (siete cabildos), sullcavi (cinco cabildos) y alapicha (cinco cabildos). El informe rechazó el intento del ex corregidor, y reafirmó el reconocimiento de los comunarios a Agustín Carbajal:

No reconosemos al Señor Masedonio Villaalta de Curaca Ricaudador del Canton Macha no sí quien nombraria, nosotros riconosemos por Curaca y 
Ricaudador al actual Agustín Carbajal que tiene su nombramiento para cuatro años [...] no podemos consentir que ningun moso nos gobierne tampoco queremos ser esclavos como el piensa como aura mismo esta aminasando con sus arrestos y comeciones es lo que pedimos en justicia (Platt y Molina, 2018, Catálogo, C5-15) ${ }^{37}$.

Está claro en este texto que Alberto Miranda no mostraba ningún prejuicio en favor del ex corregidor por haber sido «autoridad», sino que traducía fielmente al castellano escrito las protestas orales en quechua de los comunarios contra Villalta, y su apoyo para Agustín Carbajal. Miranda firmó el escrito en Liconi Pampa «a ruigo de los Ylancos y Alcaldes y de todos los Comunarios, de los espresados Aillos». Todos deben haber participado en una reunión o cabildo celebrado, en quechua, en la recaudación y en presencia del curaca.

Un recurso que utilizaban los curacas del siglo XX para imprimir su propia autoridad y autoría sobre los papeles escritos por sus escribanos eran los sellos. Agustín y su hijo Gregorio tenían cada uno su propio sello. El sello es una manera de institucionalizar la huella digital de los individuos; en principio, permite reclutar un símbolo asociado con las instancias del gobierno para dotar de estatus y autoridad a la recaudación indígena, cuyos detalles están inscritos en el sello. Se podía utilizar, tanto para personalizar y autorizar los textos en el momento de su redacción por los escribanos «a ruego del» curaca, como para reclamar un papel para el archivo después de su redacción. Entonces, para mostrar que la presencia del sello fue aprobada por el curaca para autorizar el documento desde las primeras palabras de su redacción, a veces se colocó primero el sello y después se distribuyó el texto a su alrededor.

La lámina 4 muestra esta práctica al inicio de un certificado de nombramiento del ylanco mayor de los siete cabildos del ayllu Alacollana. El certificado (Platt y Molina, 2018, Catálogo, C5-6.2.) se escribe en Liconi Pampa en presencia de «los siete alcaldes de los siete Cabildos», y se firma por Alberto Miranda «en pleno cabildo» y «a rruigo del Curaca y Agustín Carba[jal]».

Otro ejemplo de la acomodación de las líneas del texto a la forma circular del sello se encuentra en la siguiente carta escrita y firmada, a ruego de Agustín, por Alberto Miranda.

37 Para la denuncia indígena de ser convertidos en esclavos en las haciendas, compárese el Circular de Ismael Montes de 1908, cit. Platt y Molina (2018, cap. III). 

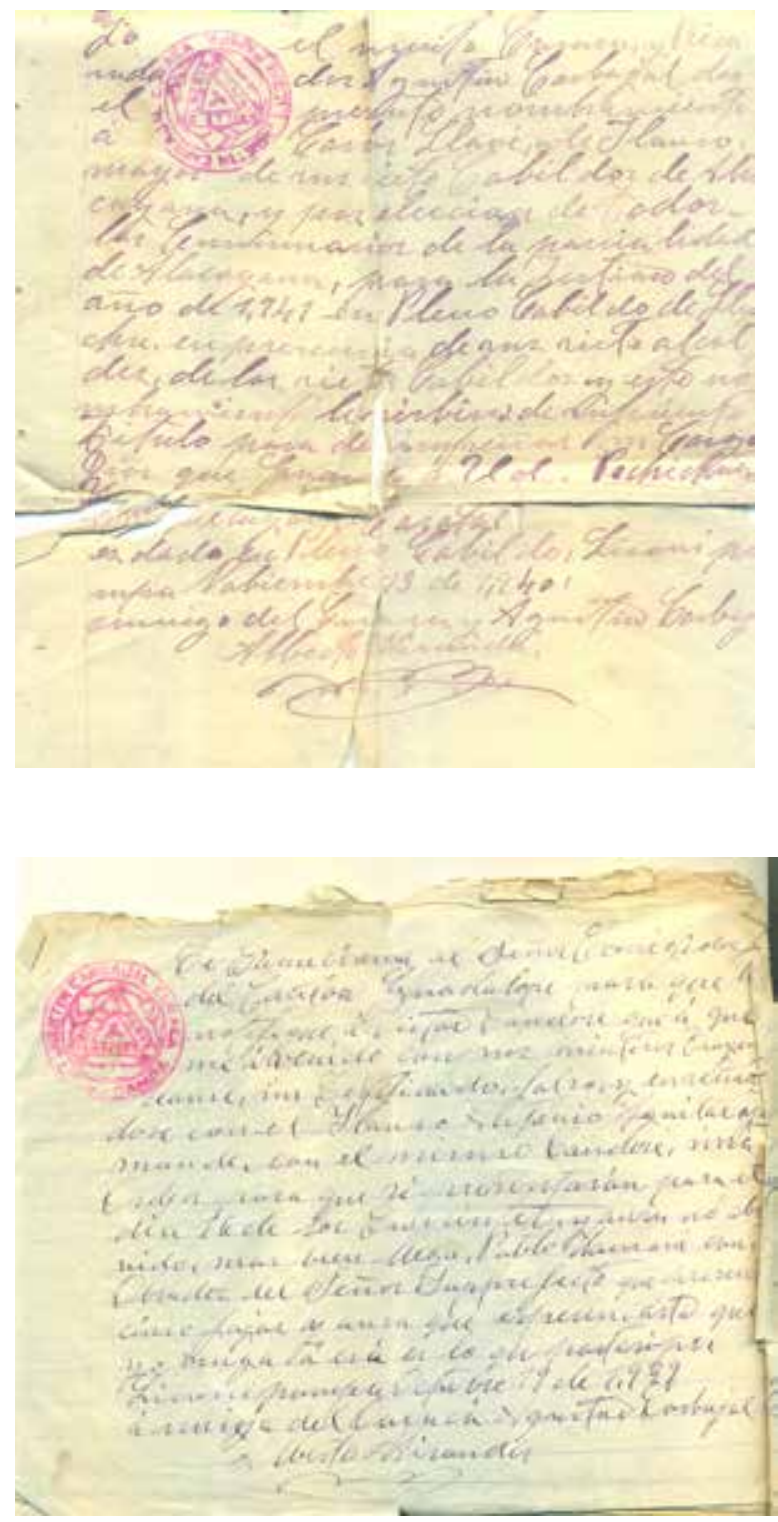

Lámina 4. Yo el suscrito Curaca y Ricaudador Agustin Carbajal doy el presente nombramiento a Carlos Llave, de Ylanco mayor de sus siete Cabildos de Alacuyana, y por eleccion de todos los Cumunarios de la parcialidad de Alacoyana, para la jestion del año de 1,941 en Pleno Cabildo de Lluchu, en presencia de sus siete alcaldes de los siete Cabildos y este nombramiento le sirbirá de suficiente título para desimpeñar su Cargo

Dios que guarde a Ud. Pichichua ... es dado en Pleno Cabildo, Liconi pampa Nobiembre 13 de 1,940: a rruigo del Curaca y Agustin Carbaj[al]

Alberto Miranda.

Lámina 5. Se comeciona al Señor Corregidor del Canton Guadalupe para que notifique a Victor Condori que a qué me ha venido con sus mentiras trayendome un certificado falso y enseñandose con el Ylanco Antonio Aguilar $\mathrm{y}[\mathrm{o}]$ mande con el mismo Condori una Orden para que se presentarán para el dia 16 de los Presintes, y aura no a benido, mas bien llego Pablo Mamani con Obrados del señor Supprefecto que presentan cinco fojas y aura que esperen, asta que yo venga a esá es lo que partesipo.

Liconi pampa Octubre 19 de 1939

A rruigo del Curacá Agustin Carbajal Alberto Miranda.

Aquí, el Curaca «comisiona» al corregidor del cantón Guadalupe para que «notifique» a un tal Víctor Condori que «¿por qué ha venido con sus mentiras trayéndome un certificado falso?», y en colaboración con el ylanco del ayllu Alapicha, Antonio Aguilar. Don Agustín había enviado una orden con Condori 
para que se presentara hacía tres días, pero «aura no ha venido», y en su lugar ha benido un tal Pablo Mamani «con obrados del señor Subprefecto que presentan cinco fojas». Como a muchos administradores, un documento largo le molestaba al curaca, más aún si no sabía leer castellano. Entonces, «que esperen asta que yo venga a esa - es lo que participo». Trasluce la impaciencia de don Agustín frente a las «cinco fojas» escritas del subprefecto y presentadas por Mamani, y su preferencia por la comunicación directa y a viva voz, en quechua, con los comunarios.

Pero la visita de Agustín al ayllu Guadalupe del Cantón Guadalupe se realizó y tuvo buenos resultados: el curaca pudo anotar otro éxito, pues el próximo año de 1940 se celebró un «acuerdo de buena amistad» entre los comunarios de los cabildos colindantes de los ayllus de Alacollana y Alapicha, ante el curaca Carbajal y el ylanco Aguilar, y bajo multa de 600 Bs en caso de incumplimiento. El debate previo fue, obviamente, en quechua. Se confirmó (por el momento) la lealtad del ayllu Alapicha con el curaca, sin tener que pasar por el subprefecto. Y el redactor del acuerdo en castellano fue, nuevamente, Alberto Miranda (Platt y Molina, 2018, Catálogo, C10-5).

Concluyo este apartado con ejemplos de la escritura de los dos hijos de Agustín Carbajal, Santiago y Gregorio, quienes terminarían reemplazando a los demás escribanos. Además de encargarse de la correspondencia oficial, ahora fueron ellos quienes redactaron los certificados, los nombramientos y los finiquitos, en castellano, para los comunarios que cumplían con los «turnos forzosos» de cobrador, alcalde e ylanco ${ }^{38}$. Ambos eran quechuahablantes, aunque sabían varias palabras del castellano. Ambos eran muy respetuosos del procedimiento notarial. Gregorio había aprendido de memoria los textos notariales en castellano para poder escribirlos repetidas veces, como parte de su trabajo administrativo ${ }^{39}$.

El primer texto que tenemos firmado en nombre de su padre por Santiago Carbajal (Lám. 6) es un Certificado de Cobrador de 1944, aunque ya desde 1942 Santiago se menciona, junto con su padre, en los recibos emitidos por el Tesoro prefectural de Potosí. Este texto repite las fórmulas estandarizadas que siempre se ponían en este tipo de documento. Debe notarse la lista de las tierras en puna y valle cuya posesión se asegura con el desempeño del cargo; en este caso, cobrador del cabildo Ayoma, ayllu Alacollana, correspondiente al semestre de Navidad de

38 Los certificados de cumplimiento de los postillones trimestrales normalmente se escribían por los maestros de posta.

39 Para el aprendizaje de memoria por Gregorio de los textos legales en castellano, ver Platt (2014, pp. 6-18). 
1943. En el siglo XIX, los nombres de las tierras se insertaban en los padroncillos y en las revisitas, vinculando así la posesión del terreno con la presencia del nombre del poseedor en la lista de tributarios revisitados. Pero en el siglo XX se habían abandonado las revisitas y la colección de la tasa quedaba en manos de los cobradores de los cabildos, los alcaldes, los ylancos y el curaca. Ahora solo los alcaldes y cobradores mantenían listas de comunarios en cada cabildo, pero sin especificar los terrenos de cada uno y sin que existiera un padrón general de todo el ayllu y de la parcialidad. Entonces las tierras se especificaban, en detalle, en los certificados de los «cargos forzosos» desempeñados por cada tributario (sea como cobrador/alcalde del cabildo, o ylanco del ayllu).

Hay que tomar en cuenta que esta práctica era un elemento importante en el orden administrativo reconstruido por los indígenas-campesinos desde principios del siglo XX, sin la gestión directa (pero con el reconocimiento de facto) del Estado, cuyo cumplimiento en beneficio del Tesoro departamental era supervisado por el curaca recaudador con su escribano, quien en este caso era su hijo mayor.

El hijo menor de Agustín, Gregorio, está representado particularmente en los años posteriores del Archivo Carbajal, sobre todo después de la muerte de Santiago en 1977. Pero ya era un devoto de la escritura desde su primer documento de 1954 (cuando tenía trece años). Sus escritos se aumentan hacia el final del gobierno de Agustín, y especialmente cuando él mismo asume el Curacazgo entre 1981 y 1994. El certificado de la Lámina 7 está escrito a máquina en 1984 (Gregorio tenía una vieja Underwood), y lleva un nuevo sello correspondiente a «Gregorio Carbajal 'Curaca'» colocado como colofón al final.

Como ya se mencionó, en una conversación con Gregorio realizada poco antes de su muerte, en diciembre de 2014, el viejo curaca nos contó, en quechua, cómo había memorizado todo el texto notarial en castellano que correspondía a los certificados. En medio de una disquisición en quechua, repetía en voz alta el texto en castellano, poniendo nombres, lugares y cargos como ejemplos. Dijo (en quechua) haber escrito cientos de certificados de esta manera ${ }^{40}$. Los que se encuentran en el archivo son unos pocos borradores o copias: Gregorio siempre se empeñaba en escribir, y a veces producía varios ejemplares del mismo documento.

Una última cita mostrará cómo Gregorio manejaba el sistema que él mismo alimentaba con documentos. Una de las funciones de todas las firmas y los sellos era que podían ayudar a rastrear personas, papeles y dineros perdidos. Aquí Gregorio escribió sobre un semestre de la contribución que faltaba del «Cabildo

40 Para una transcripción de una parte de esta conversación, ver Platt (2014). 
Cabreca». Cabreca es una aldea histórica perteneciente al ayllu Sullcavi (cabildo «Cabreca Cariporco»), ubicada en las quebradas que bajan desde las alturas de Colquechaca y de la zona intermedia (chawpirana) de Surumi, hacia el Jatun Mayu, o Río Grande, y los valles de San Marcos (ver Mapa).

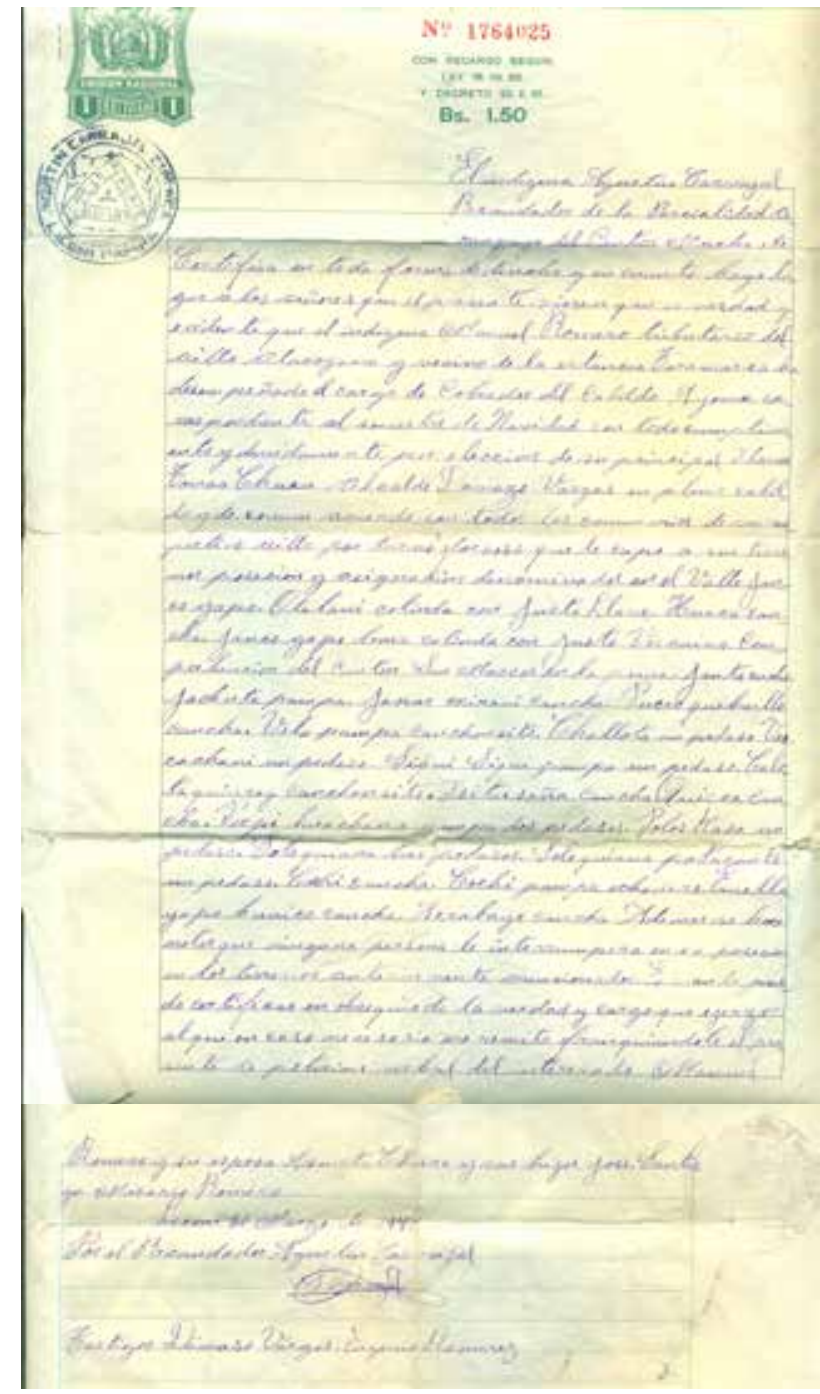

${ }^{41}$ Los dos testigos también son indígenas.
Lámina 6. Agustín Carbajal certifica con su sello, y en papel sellado del Estado, que el indígena Manuel Romero tributario de la estancia Taramarca del Cabildo Ayoma, Aillo Alacoyana, y su esposa Asunta Chura con sus hijos, han desempeñado el cargo de Cobrador del Cabildo correspondiente al semestre de Navidad [...] por turno forzoso, con lista de terrenos de puna y valle. Por el Recaudador Agustín Carbajal. [Escribano] $\mathrm{S}<$ antiago $>$ Carbajal. Testigos: Dámaso Vargas [alcalde]. Eugenio Ramírez. Leconi, 20 de marzo de 1944 (ver Platt y Molina, 2018, Catálogo, C1-20r-v). ${ }^{41}$ 


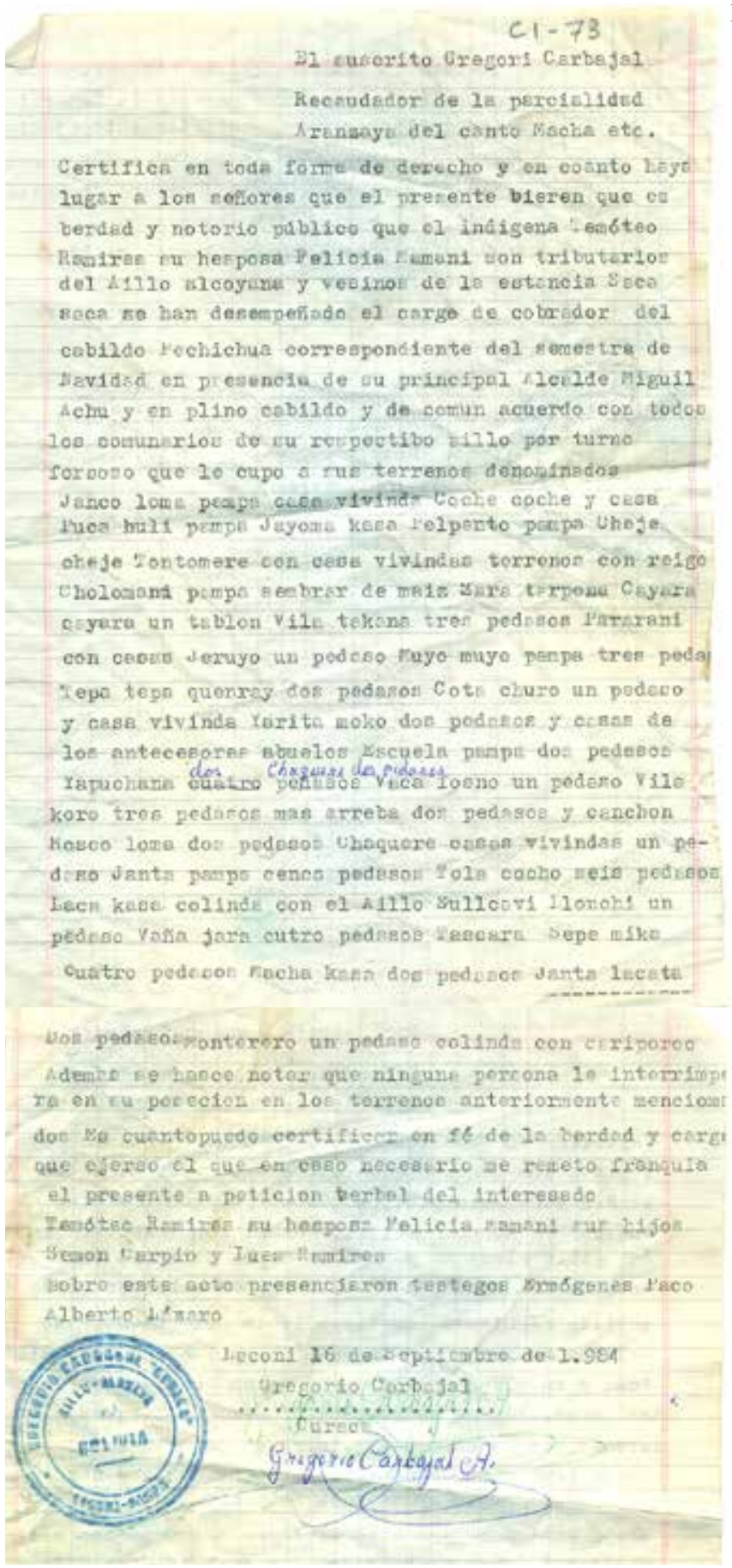

Lámina 7

cherst to hyerort Carbejal 
Otro informe del Cabildo Cabreca falta un semestre del año pasado 1975 por fabor mandame esa cobrador se llama filiciana $\mathrm{O}$ otro cual sera controlanse de sus documentos y finiquitos seran con me sello y firma tienen que pagar sancion enteres asi se tiene Orden del Señor tesoro de Partamental de Potosí $(\mathrm{C} 1-58 \mathrm{v})^{42}$.

Se trata del reintegro de impuestos devengados que habían faltado en 19751976, debido al alza resuelta desde el segundo semestre de 1975 por el prefecto de Potosí (Platt y Molina, 2018, Catálogo, C1-52, C1-53). Para resolver el problema, Gregorio apeló a su propia práctica administrativa («controlanse de sus documentos y finiquitos seran con mi sello y firma») para facilitar la identificación de una cobradora (se trata de una mujer sin hermanos, o quizás viuda) que adeudaba un semestre de contribución a la recaudación.

Desde principios del siglo XX, los curacas recaudadores de Macha Alasaya tenían forzosamente que administrar sus parcialidades echando mano de los servicios de escribanos-bilingües, pues los nuevos recaudadores indígenas no eran bilingües como los recaudadores criollo-mestizos de principios de la República. Ahora el curaca recaudador indígena de Alasaya era quechuahablante, con mucha experiencia política y del mundo más allá de su parcialidad, pero sin castellano; entonces, la responsabilidad que correspondía a los bilingües recaía necesariamente sobre letrados mestizos del Cantón. En los primeros años (1912-1924) se recurrió a menudo al corregidor letrado de Macha; después, y especialmente con el curacazgo de Pedro Ramírez (1926-1936), los escribanos bilingües crecían en número y relevancia. Al mismo tiempo, fueron los curacas monolingües en quechua quienes sabían defender mejor las tierras y los derechos de sus comunarios: los escribanos bilingües dependían de ellos, y de sus conocimientos, para poder formular los mensajes escritos que debían trasmitir en castellano.

En general, parece que los escribanos bilingües se identificaban con su trabajo, respondiendo a la confianza depositada en ellos por un curaca «cerrado al quechua». Se trataba de una relación de colaboración que también se extendía ocasionalmente a otros letrados en los pueblos, a veces compadres, dispuestos a firmar «a ruego» del curaca. La situación en el siglo XX era muy diferente de la que se había dado a principios de la República, cuando los recaudadores criollo-mestizos eran vecinos de los pueblos y, aunque bilingües y dispuestos a

42 Gregorio quizá pensaba en el Memorándum del Tesoro Administrativo enviado a su padre en 1973: «Caso de no dar cumplimiento se les aplicará el recargo e interes respectivo». Citado en Platt y Molina (2018, Catálogo, C1-49). 
favorecer a «sus» campesinos en las cortes, enfocaban su principal interés en la producción de los «comunes» de «su» parcialidad, mini haciendas cuya producción les servía, con el trabajo de «sus» indios y durante el período de su cargo, para pagar la contribución territorial anticipadamente, y como fuente de capital para sus negocios.

\section{LOS PASQUINES DE LOS «ALCALDES MAYORES» (1936-1946)}

Ahora bien, hubo un grupo de campesinos-activistas en la primera mitad del siglo XX que respondieron a la situación diglósica de otra manera. En los años 1920 y 1930 surgió un nuevo movimiento en La Paz, que terminó separándose del movimiento mejor conocido de los caciques apoderados, conducido por Santos Marka Tola, cacique principal de Callapa en Pacajes, y desde 1919 apoderado principal de todos los caciques de Bolivia (Taller de Historia Oral Andino, 1984; ver también, Rivera Cusicanqui, 1991; Gotkowitz, 2007). Se llamaban los «Alcaldes Mayores» y tenían un impacto directo en Macha a través de un alcalde mayor de ambas parcialidades de Macha, José Caicina, quien probablemente fuera el responsable de introducir al archivo de Agustín Carbajal la documentación que ahora veremos ${ }^{43}$.

El papel de los alcaldes mayores particulares entre las redes políticas de los campesinos bolivianos durante la primera mitad del siglo XX ha venido esclareciéndose gracias a los trabajos de Waskar Ari (Arias, 1994, Ari-Chachaki, 2008-2010; también, Ari, 2014). Este autor se basa principalmente en una serie de archivos privados que pertenecen a varios campesinos y autoridades indígenas de La Paz, Oruro y Chuquisaca. Sobre la base de estos papeles privados y muchas entrevistas, Ari sostiene que, según los «alcaldes mayores particulares» Gregorio Titiricu y Toribio Miranda, la búsqueda de viejos títulos predicada y practicada por Santos Marka Tola, y algunos de sus poderdantes, era una tarea sin futuro. Más importante para los alcaldes mayores eran la lengua y la religión aimaras, plasmadas en el culto cosmopolítico a «los Achachilas y la Pachamama», a tal

43 Durante la Colonia temprana, las Alcaldías Mayores eran los cargos más altos a que podía aspirar un indígena en los Andes (en México estos cargos fueron ocupados por españoles). Ver Espinoza Soriano (1960); Platt et al. (2011 [2006], pp. 673-685). Actuaban como una especie de justicia mayor para los indios, al lado y bajo la autoridad del corregidor de la provincia. La recuperación del título en el siglo XX responde a la lectura por los campesinos indígenas de documentos antiguos, tal como fue recomendado por diferentes caciques apoderados $\mathrm{y}$ también por los mismos alcaldes mayores (Ari, 2014). 
punto que los alcaldes mayores fueron llamados «pachamámicos» por otros activistas indígenas (Ari, 2014, p. 8).

Se trata de un resumen escueto del complejo y variado sistema de conocimientos y prácticas locales que expresan, hasta hoy, la devoción andina. Como veremos, los alcaldes mayores pensaban que esta religión procedía del «tiempo de la obscuridad», o sea de los chullpas «presolares». Al mismo tiempo, solían llevar el tomo VI de la Recopilación de Leyes de Indias (tomo que incluye la legislación del rey Felipe II) a sus reuniones. Y también enfatizaron la importancia de las escuelas particulares, donde el curriculum y el idioma de enseñanza deberían ser decididos por los mismos campesinos.

A diferencia del cacique apoderado Santos Marka Tola, Toribio Miranda proyectaba su mensaje desde el Altiplano también hacia los colonos de las haciendas de los valles de Chuquisaca y no solo a los llamados «ayllus libres» de la puna. Difería en este respecto del cacique apoderado, más orientado hacia la defensa general de los ayllus altiplánicos mediante un nuevo deslinde de tierras entre haciendas y ayllus (Rivera Cusicanqui, 1991, p. 612). A partir de 1936, los alcaldes mayores empezaban a distribuir pasquines, impresos o escritos a mano, para difundir su mensaje político y movilizar apoyo. De ahí que encontramos en el archivo del curaca tres pasquines escritos a mano, que dan ejemplos de los nuevos discursos que circulaban en el campo norpotosino entre 1936 y 1946 (los dos años mencionados en estos textos). Quizás en 1946 se trataba de un nuevo esfuerzo de los alcaldes mayores de circular sus pasquines para articular sus redes en las circunstancias políticamente críticas de aquel momento. Además, muestran de manera elocuente la lucha por apropiarse del castellano, en medio de la diglosia liberal-criolla que se libraba por este nuevo grupo de activistas ${ }^{44}$.

Según Ari, los alcaldes mayores buscaban formular una Ley India basada en la «República de Indios» colonial, como una «república» distinta de la «República de Españoles». En el pasquín que examinamos, se refiere igualmente a la «Ley de los Indios», «la ley indios Campesinos de la antigüedad / Felipenalis». Como veremos en seguida, «Felipenalis» es una palabra que recurre en los pasquines y alude al tomo VI de la Recopilación de las Leyes de Indias. Así, la separación colonial de Indios y Españoles les parecía a los alcaldes mayores como un útil recurso defensivo, un «apartheid» que convenía a los campesinos recolonizados, y la solución más adecuada para resolver las condiciones de racismo, menosprecio

44 Para los documentos originales, ver imágenes en Platt y Molina (2018, Catálogo, C12-3.1, C12-3.2, C12-15). 
y violencia que tenían que soportar a manos de los patrones, de la Rosca, incluso de obreros, y de autoridades criollo-mestizas en Bolivia antes y después de la Revolución de 1952.

Algunas palabras antes de leer el texto de uno de los pasquines: todos están escritos en un castellano cuyo estilo y ortografía están influenciados por el aimara. Deben ser leídos con atención, porque muestran la construcción de una nueva forma de lenguaje escrito. Pero vistos a la luz de la historia y la literacidad campesinas, adquieren el significado de una rememoración histórica y poética, además de una denuncia política. Pienso que estos pasquines revelan mejor su significado si se los lee en voz alta y con rabia... Son la evidencia de que hubo varios «Waman Pumas» en Bolivia en los años anteriores a la Revolución de 1952.

El pasquín que presentamos aquí ${ }^{45}$ lleva tres sellos, dos de ellos correspondientes a un tal Isaac Mamani (no mencionado por Ari) con la leyenda: «Alcalde Mayor de la Altiplanicie Campesina, Estrada Lagunilla Colcakagua, Prov. PariaMisque». Se posicionan casi al final del texto, antes del último párrafo (no está claro por qué se repite este sello y firma). El otro sello, situado entre los dos de Mamani, es de Vicente Maraza, «Alcalde Escolar Particular, Altiplanicie Campesina Chulla ${ }^{46}$, Provincia Charcas, Paria Mizque» (quizás = «desde Paria a Mizque»). Vicente Maraza tampoco es mencionado por Ari, pero puede ser hijo o pariente de Feliciano Inka Maraza, quien sí aparece en el libro de Ari, y también (sin el título de «Inka») entre los poderdantes de Santos Marka Tola (ver Platt y Molina, 2018, Apéndice 3). Ya hemos visto la importancia de los sellos, en esta misma época, dentro del aparato simbólico-político de los curacas recaudadores de Macha.

Estos textos son complejos, porque combinan elementos discursivos procedentes de diversas fuentes y períodos históricos, agrupados lapidariamente, que requieren comentario; al mismo tiempo, sugieren una mimesis en el siglo $\mathrm{XX}$ de las formas escritas de la autoridad colonial (ver, por ejemplo, las referencias a «la Ciudad de La Plata», a «tierra firme y firme oesciano», y la repetición notarial «etc. etc.»). Reproduzco aquí uno de los pasquines (C12-3.1), seguido por una transcripción literal:

45 Este análisis también se encontrará con mayor contexto en Platt y Molina (2018, cap. III).

46 Posiblemente chulla = choclla, ««choza campesina»; ver análisis del texto abajo. 

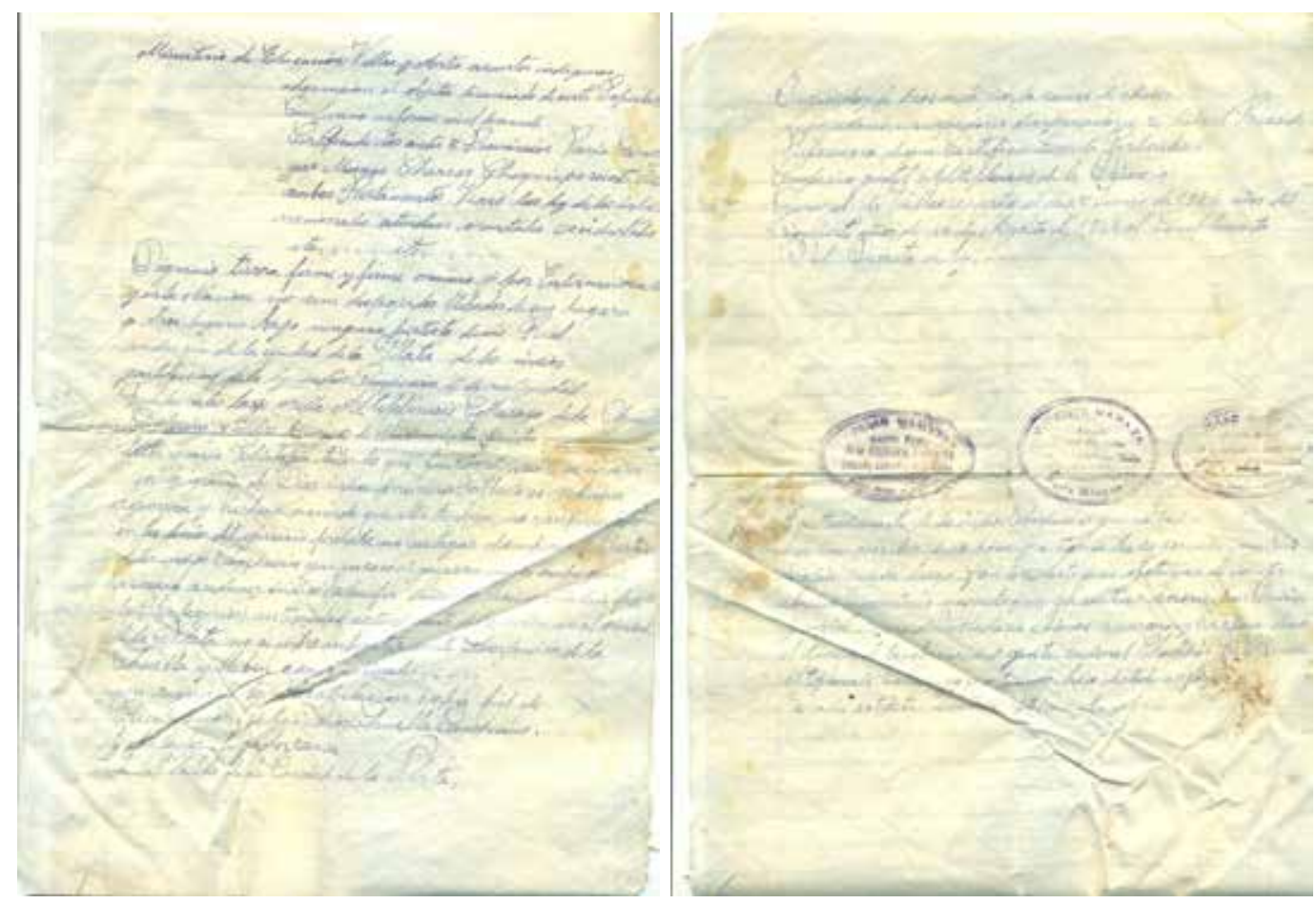

Lámina 8. Pasquín de los alcaldes mayores Isaac Mamani y Vicente Maraza, con sellos. «Agosto de 1936 y junio de 1946» (C12-3.1).

[Transcripción del Pasquín en Lám. 8:]

[1r] Ministerio de Educación Villas y Artes asuntos indígenas, adquisición de objitos licenciado de ante Popular Campesino informe en el presente Certificado los antes 5 Provincias Paria Caran gas Misque Charcas Choquiapo siento de los ambas Partamentos Viais las ley de los indios nacionales atendais orentales occidentales etc.... etc....

Digranio tierra firme y firme oesciano y por Enternacionales y en la Nación no sean despojados llebados de sus lugares a otros lugares bajo ninguna pertseto de mi Real audiencia de la ciudad de la Plata de los indios Gentilz[a]ción de la ley indios Campesinos de la antiguedad Felipenalis lago orilla Altiplinecie Collasuyo de la Chuclla Campesino y indios primeros de Nacimientos puistos por Tribo granio Edeolojia todos los que fueron presente se indios por la gracia de Dios indios primeros Pobladores ydioma aymara y kichua aciendo que ellos tambien no conprendidos 
en las linias del ejercicio prohibe no castigar desamparar de libertar a las indios Campesino que en caso de guerra no se embee gente armada a reducer indios Filosufia Señuríos Viais y atendais por la Berefecacion actualmente de los indios en el ciudad de La Plata no se enbee enbientar gente Campesino de la Chuclla y lleben como animales....

Que sigun la ley Recopelacion copia fiel de Recopelacion de los indios Chuclla Campesino, trabajador labrador causa de la Villa de la Ciudad de La Plata, [1v] dique doy fe traslado por la causa de abusos dispojadores usurpadores disaparicidores se lí da el Presente Riferencia de que Certifico Escuela Particularis Campesino gentil Altiplanecie de la Direccion General de Villas y Artes el dia 5 junio de 1946 años del sigueinte años de 19 de Agosto de 1936, al Complemento Del Decreto de Liy...

[3 sellos]

Isaac Mamani

Alcalde Mayor

De la Altiplanicie Campesino

Estrada Lagunilla Colpakahua

PROV PARIA - MISQUE

Vicente Maraza

Alcalde

Particular Escolar

Altiplanicie Campesino Chu[k]lla

Provincia Charcas

Prov Paria y Mizque

Isaac Mamani

Alcalde Mayor

De la Altiplanicie Campesino

Estrada Lagunilla Colpakahua

PROV PARIA - MISQUE

Hactualmente de los indios Campesinos que no sabia leer ni escriber pero poco ya tienen ha se escuela yen sus Propios rededor luego yen presente que obstengan de cometer abusos vigamines y nos otorgan garantías porque son Duiños propios premeros Pobladores idioma aymara y Kichua desde el tiempo de la obscuridad gente cadenal Chullpas Felipenales Altiplanecie Collasuyo y Antisuyo hiso diclade informe sera la estricta Justicia etc... etc... 
El propósito del texto es despertar un coro de reconocimiento a lo largo de las redes creadas y articuladas por los alcaldes mayores, por donde pasaban los pasquines; y movimientos de protesta contra los abusos violentos y las prácticas arbitrarias citadas. El texto logra sus efectos por la fuerza retórica del nuevo lenguaje hispano-indianista inventado y movilizado, junto con su ordenamiento en un formato derivado de los documentos coloniales y republicanos de poder. Así, los dos alcaldes mayores aimarahablantes ostentan, a su manera, las formas escritas de la autoridad desplegada por las fuerzas hispánicas (neo)coloniales y republicanas. $\mathrm{Su}$ objetivo es expropiar y reorientar esta autoridad para enfrentar los «abusos vigamines», exigir «garantías» y dar justicia a los «primer Duiños propios premeros Pobladores idioma aymara y Kichua». Se trata de recuperar la ley justa y antigua de «mi real Audiencia», la que defiende a los «indios primeros de nacimiento» $\mathrm{y}$ «puistos por tribu», aunque haya sido pisoteada en tiempos recientes. Veamos algunos de los temas y elementos de esta compleja y poderosa estrategia retórica.

En el primer párrafo, se refiere al «Ministerio de Educación, Villas y Artes Asuntos Indígenas», quizás como lugar de origen y encabezamiento del documento. El Ministerio de Asuntos Indígenas fue establecido por el presidente Villarroel antes del Ministerio de Asuntos Campesinos, que lo reemplazó después de la Revolución de 1952. El MNR de Víctor Paz Estenssoro cambió «Asuntos Indígenas» por «Asuntos Campesinos», reemplazando la referencia étnica, que había sido el criterio del esfuerzo descolonizador del Congreso Indigenal de 1945, con otra de clase más acorde con la visión liberal-nacional del nuevo gobierno post-revolucionario (y también con el sindicalismo minero).

«Villas [y] Artes» es una modificación de la frase «Bellas Artes». El desarrollo del «arte popular», especialmente el arte textil, fue visto en círculos indigenistas — sobre todo en México — como una «vía de desarrollo» para los «indios» del hemisferio. En otro pasquín, los alcaldes mayores reconocen el arte de las mujeres indígenas: «tejetura elandira» (= tejedora, hilandera) (cf. Platt y Molina, 2018, Catálogo, C12-15). Como en la «choclla campesina» (choclla = choza), se sitúa la creatividad de los indios y de las indias en la casa doméstica de la sociedad rural, en cuyos alrededores debían construirse las escuelas particulares.

La enunciación de «los antes 5 Provincias» de Carangas, Paria, Mizque, Charcas y Choqueyapo [= La Paz] refleja una regionalización de los Andes centrobolivianos cuyos antecedentes no se conocen ${ }^{47}$. Se alude a las tres provincias

47 El discurso de los «señoríos» es un reclamo político que anticipa la posición de CONAMAQ (Consejo Nacional de Ayllus y Markas del Qullasuyu), organización constituida en 1997. 
mencionadas en los sellos de los alcaldes mayores («Paria-Mizque»y «Charcas») (cf. Ari, 2014). Se distinguen las provincias de «ambas Partamentos», aludiendo a «la Ley de los Indios nacionales» («¡Veáis!»), y aclarando («iatendáis!») que se trata de una alianza entre el Occidente y el Oriente del país.

El segundo párrafo empieza con el vocablo «Digranio» (líneas abajo se repite «granio»), que posiblemente deriva de una frase común de autorización en los documentos de la colonia temprana: «del reino» ${ }^{48}$. Sigue una alusión a otra frase común en las declaraciones coloniales de la Corona («océano y tierra firme»), y la denuncia central del pasquín contra el reclutamiento violento de los campesinos por el Ejército, práctica que seguía en el campo años después de la Guerra del Chaco con miras al servicio militar obligatorio.

Luego se invoca la autoridad colonial de la Audiencia de La Plata, y la «Ley India» de los campesinos de la antigüedad, con la frase ya vista: «primeros de Nacimientos puestos por tribu». Sigue la palabra «iideología!», quizás una llamada a una toma de conciencia.

La palabra «felipenales» aparece dos veces en este pasquín, y también en un pasquín impreso publicado por Ari (2014: 66). Se refiere, probablemente, a la legislación sobre los indios en el Libro VI de la Recopilación de las Leyes de Indias (1680), que recoge leyes promulgadas por el rey Felipe II con fecha de 24 de diciembre de $1580^{49}$. Ari considera que estas leyes eran de interés particular para los alcaldes mayores. En el archivo del curaca, también encontramos al final del presente texto la frase «la ley Recopilación copia fel de Recopelacion de los indios Chuclla Campesino».

En otra parte del texto se repite la oposición de los campesinos a las patrullas militares de reclutamiento:

en las linias del ejercicio prohibe no castigar desamparar de libertar a las indios Campesino que en caso de guerra no se embee gente armada a reducer indios / Filosufia / Señuríos / Viais y atendais / por la Berefecacion / actualmente de los indios en el ciudad de La Plata / no se enbee enbientar gente Campesino de la Chuclla y lleben como animales .... [cursivas mías, TP]

Aquí se protesta contra los reclutamientos forzados, antes, durante y después de la Guerra del Chaco, y se alude a la «Filosufía» de los indios. «Señuríos», también denominados «naciones» en el tardío siglo XVI, era el nombre colonial

\footnotetext{
48 Agradezco esta sugerencia a Vincent Nicolas.

49 http://gabrielbernat.es/espana/leyes/rldi/indice/indice.html
} 
de la antigua organización social de los «primeros pobladores» surandinos, que debían ser respetados: «iviais y atendais por la Berefecación!». El uso de la palabra «señorío» muestra otra vez el acceso por los alcaldes mayores del siglo XX a expedientes de la Colonia temprana ${ }^{50}$.

En el siglo XX también era ilegal (según el Circular Supremo de Ismael Montes de 1908, citado en 1937 por Agustín Carbajal en una apelación al Ministerio de Defensa en $\mathrm{La} \mathrm{Paz}^{51}$ ) enviar a gente armada para «reducirles» a los primeros pobladores, o sea, los «Campesinos de la Chuclla [la Choza]», y «llevarles como animales» a la Guerra. Fue prohibido, se dice en el pasquín, por dos razones distintas: las leyes antiguas y la antigüedad de los campesinos en la tierra ${ }^{52}$.

Las tres palabras elegidas para referirse a los que cometían abusos son particularmente impactantes:

¡Dispojadores! ¡Usurpadores! ¡Disaparicidores...!

Aquí se alude con furia y desprecio a toda una historia de robos, expropiaciones y masacres.

Un postscriptum insiste en la necesidad de las escuelas particulares (uno de los objetivos principales de los alcaldes mayores, ver Ari, 2014, p. 100), que ya se encontraban «en sus propios alrededores». Al mismo tiempo, enfatiza la importancia de los idiomas nativos «desde tiempo de la obscuridad», o sea, desde los Chullpas, cuando supuestamente solo hubo la religión de la Tierra y de la Luna, y desde los «Felipenales»:

Hactualmente de los indios Campesinos que no sabia leer ni escriber / pero poco ya tienen ha se escuela y en sus Propios rededor / luego yen presente que obstengan de cometer abusos vigamines / y nos otorgan garantías / porque son Duiños propios / premeros Pobladores idioma aymara y Kichua / desde el tiempo de la obscuridad / gente cadenal Chullpas Felipenales / Altiplanecie Collasuyo y Antisuyo / hiso diclade informe / sera la estricta Justicia etc ... etc ...

50 Para ejemplos de estos expedientes en el Archivo de Agustín Carbajal, ver Platt y Molina (2018, Catálogo, C13 [Historia]).

51 Ver Platt y Molina (2018, Catálogo, C5-46.1-5).

52 Vale notar que este doble aspecto del derecho campesino a la tierra, planteado por los autores del pasquín, coincide con la distinción que hace Jacques Derrida (1997) entre los dos principios presentes en el Archivo: el nomotético (la ley del archeion) y el ontológico (la primordialidad secuencial). 
Aquí sobresale, en primer lugar, una preocupación con la lectura y la escritura, y con la escuela rural como fuente local de alfabetización en el siglo XX, y en segundo lugar, la demanda de «garantías», que (como señala Ari) era una de las palabras claves en el lenguaje de los alcaldes mayores ${ }^{53}$.

La frase «lago orillas» nos refiere al espacio de origen de los alcaldes mayores, articulado por el «eje acuático» que va desde el lago Titicaca por el río Desaguadero hasta los lagos Uru-Uru y Poopó (ver mapa), y después al lago Coipasa. En este mismo espacio vivían «los Duiños propios premeros pobladores [de] idioma aymara y Kichua desde el tempo de la obscuridad... Chullpas Felipenales»: o sea, los urus de los lagos y de los ríos, y los chipayas del lago Coipasa del tiempo del rey Felipe. Con la frase «el tiempo de la obscuridad», el pasquín se refiere al conocido mito de los chullpas que vivían antes de la subida del Sol incaico. Debe notarse que el texto del pasquín atribuye erróneamente los idiomas quechua y aimara a «los premeros pobladores», sin mencionar la lengua de los uru-chipayas.

¿Cómo llegaron estos textos al archivo? Ya hemos visto que los pasquines empezaban a redactarse, probablemente en La Paz, en 1936, y en Macha, habrían llegado primero a manos del alcalde mayor de Macha Alasaya y Majasaya, José Caicina, para ser circulados (si es que él mismo no los hubiera traído desde el norte). Por otra parte, la fecha « 5 junio de 1946» sugiere una nueva ola de pasquines, (re)copiados y circulados quizás como respuesta y repudio a la prepotencia rosquera en un momento cuando los participantes del Congreso Indigenal de mayo de 1945 se encontraban nuevamente perseguidos por hacendados, mosos y militares. El 5 de junio se aproximaba al 21 de julio de 1946, cuando el presidente Villarroel, patrocinador del Congreso Indigenal de 1945, sería linchado en La Paz. Es muy probable que se encuentren otros pasquines de los alcaldes mayores del siglo XX, distribuidos en esos años entre archivos todavía desconocidos del norte de Potosí y otras regiones.

El pasquín que hemos leído es parte de un trabajoso intento de expresar, en un castellano reinventado a partir de lecturas de documentos coloniales y un etnorreportaje apasionado de acontecimientos contemporáneos, la situación de discriminación neocolonial en que se encontraban inmersos los autores y su gente. En los términos de este capítulo, se trata de un esfuerzo titánico de romper la cárcel de la diglosia, apropiándose del idioma de la dominación, y transformándola hasta crear un nuevo medio de expresión justiciero y libertario.

53 Para las «garantías» en Macha Alasaya, cf. Platt y Molina (2018, Apéndice 4). 
Al mismo tiempo, se puede decir que los autores son, ellos mismos, intérpretes, en cuanto traducen su propia situación política y cultural, percibida en términos aimaras, a nuevos términos andino-castellanos, y a la vez escribanos, que inscriben sus traducciones al papel, utilizando el vocabulario y el formato de los documentos coloniales que han escudriñado. Es decir, los autores indígenas de los pasquines han asumido la posición distintiva de intérpretes-escribanos, tal como hicieron en Macha los escribanos bilingües mestizos del curaca Pedro Gómez y Alberto Miranda. Y en este caso, el estilo amalgamado de su texto permite a los alcaldes mayores Isaac Mamani y Vicente Maraza, autores del pasquín, proyectar desde la «altiplanicie campesina» una denuncia llena de indignación y horror, al mismo tiempo que restauran una visión mitohistórica del pasado como sostén de la justicia reclamada en el presente.

El resultado es desgarrador. Y los autores intentaron amplificar su mensaje distribuyendo los pasquines, entre los aimarahablantes del Altiplano hasta el norte de Potosí y, quizás, a José Caicina de Macha. Así llegaban a manos del curaca quechuahablante de Alasaya, Agustín Carbajal, quien los depositó en el archivo de la Recaudación, quizás para que uno de sus «escribanos-bilingües» le hiciera la traducción al quechua. Es probable que otros ejemplares hubiesen sido entregados por Caicina al entonces curaca de Macha Majasaya, Martín Mamani, cuyo archivo aún no se conoce.

\section{EL DESENLACE}

Las tres situaciones que hemos examinado a través de documentos del Archivo Histórico de Potosí y del Archivo del Curacazgo de Macha Alasaya, pueden situarse ahora, a grandes rasgos, en la temporalidad de la República desde 1830 hasta 1994. El replanteamiento por los ayllus del pacto tributario con el Estado durante la primera mitad del siglo XX fue buscado y preparado desde antes de la Guerra Federal de 1899, sobre todo como respuesta a las políticas del gobierno, tales como la Ley de Exvinculación de las tierras de comunidad (1874), y la revisita que se implementó hasta poco después de la Guerra Federal (Platt, 2016 [1982]).

En el siglo XX, don Agustín Carbajal pudo desarrollar su proyecto exitosamente hasta la Revolución de 1952. Pero pronto, y a pesar de su deseo de seguir entregando la Contribución, el ritmo de la recaudación fue roto, primero, por el subprefecto movimientista de Colquechaca, Wilver Chacón, quien nombró a un nuevo curaca, Ramón Cabezas, pese al apoyo que la mayoría de los Ayllus seguían dando a Agustín Carbajal (Platt y Molina, 2018, Catálogo C1-31), y segundo, por 
los sindicatos del $\mathrm{MNR}^{54}$. Gracias a los papeles del archivo del curacazgo de la familia Carbajal, ahora comprendemos mejor el impacto político de la marginación de Agustín desde 1954 hasta 1961, y las razones detrás del apoyo dado por el curaca al golpe de René Barrientos en 1964 (Platt y Molina, 2018, Caps. IV-V).

Hace tiempo sostuve que, después de la Guerra Federal boliviana de 1899, todos los contendores - hacendados y mineros criollos, pequeños productores mestizos, y ayllus indígenas - expandían sus espacios respectivos de poder y autoridad sin llegar a ningún desenlace definitivo (ver Platt, 1991[1987]). En este texto, y con el archivo del curaca de Macha Alasaya recién disponible en su totalidad, he señalado una de estas líneas de expansión: la lucha por la autonomía que se dio en Potosí durante la primera mitad del siglo XX por los curacas recaudadores, monolingües en quechua, con la ayuda de sus escribanos-intérpretes bilingües en quechua y castellano. Esta lucha fue fundamentalmente para liberarse del proceso desencadenado por las políticas agrarias parcelarias del liberalismo criollo del siglo XIX (Platt, 1984[1991]).

Partiendo del Código de Procederes Santa Cruz, hemos señalado tres hitos en la historia de los bilingüismos en el Norte de Potosí desde 1834 hasta la primera mitad del siglo XX. Dentro del marco envolvente de la diglosia colonial-republicana, se ha visto cómo, después de la Guerra Federal de 1899, el intérprete-escribano bilingüe se transformó en Macha desde la autoridad criollaciudadana del siglo XIX (jueces de Paz, recaudadores, etc.) al profesor normalista de Macha, Pedro Gómez, quien servía de escribano al curaca monolingüe en quechua antes y después de la Guerra del Chaco. Sin embargo, la autoridad política quedaba en manos del curaca, como encargado de la recaudación y de la entrega de la tasa al Tesoro departamental. Su gobierno dependía no solo de los escribanos, sino del apoyo y reconocimiento dado por las autoridades menores, los comunarios y los cabildos de su parcialidad, todos sujetos a los cargos fiscales de turno. Este contexto social contribuye a explicar por qué los dos escribanos bilingües que hemos conocido, Pedro Gómez y Alberto Miranda, eran leales a la visión política del curaca.

La misma fusión de intérprete y escribano se observa en los autores de los pasquines que circulaban desde los Alcaldes Mayores del Altiplano a los del Norte de Potosí en los años 1930 y 1940 . Aquí se trataba de un intento por los

54 Para la historia anterior de los sindicatos entre los ayllus y ex colonos de Cochabamba, ver Dandler (1969), Gordillo (2000), Gotkowitz (2007). Para Ramón Cabezas, ver el informe del ylanco Santos Chambi del 16 de marzo de 1953 en Platt y Molina 2018 (Cap. 4 y Catálogo, C5-40). 
aimarahablantes de La Paz de apropiarse del idioma dominante, el español, forzando y reinventándolo para servir sus propósitos políticos, como autores y probables escribientes de los pasquines. El lenguaje de los pasquines, su estilo literario y su formateo retórico, intentan apropiarse de un histórico discurso de poder que refleja y recoge los documentos coloniales leídos por sus autores ${ }^{55}$.

Entonces, si dejaron de existir los intérpretes profesionales en el norte de Potosí republicano, fue porque sus funciones pudieron llenarse por los escribanos y letrados bilingües. Pero detrás de esta fórmula subyacen situaciones diferentes. A principios de la República, se trataba de los jueces, los recaudadores y otras autoridades ciudadanas, bilingües en español y aimara. Después de la Guerra Federal aparecieron los «escribanos de comunarios» ${ }^{56}$, bilingües en español y quechua, que servían y ayudaban a los curacas a llevar a cabo las responsabilidades de la recaudación. En cambio, los alcaldes mayores procedentes del lago Titicaca y del Altiplano Norte, letrados y parcialmente bilingües en aimara y español, usaron el español como la «materia prima» para crear una lengua franca escrita hispano-indianista, cuyo mensaje llegó al archivo de Agustín Carbajal, gracias, sin duda, al alcalde mayor de Macha José Caicina.

La autoridad del curaca recaudador seguía consolidándose hasta la Revolución de 1952, con el apoyo de los ylancos y los alcaldes de turno. Los actos de escritura de los «escribanos de comunarios» bilingües se dirigían por un curaca elegido por gente igualmente analfabeta y monolingüe en quechua, que confiaba en su experiencia, constancia y sagacidad. Y con el apoyo de los cabildos de los ayllus, Agustín estaría confirmado regularmente entre 1937 y 1949 como curaca por el subprefecto provincial en Colquechaca.

Así, la Revolución de 1952 fue precedida en Macha Alasaya por un largo y empedernido trabajo desplegado desde principios del siglo por curacas y recaudadores, con sus escribanos bilingües, y apoyados por los veinticinco cabildos y cinco ayllus de su parcialidad. Su objetivo era reconstruir un «pacto de reciprocidad» entre la parcialidad y el Estado (ver Lám. 8), junto con la aplicación de la ley por igual a todos los bolivianos. Frente al impacto de corregidores, mosos y militares antes y después de la Guerra del Chaco, algunos alcaldes mayores apelaron a las dos Repúblicas coloniales «de españoles» y «de indios», para justificar una ley y una política étnica propia, independiente de una corrupta administración

55 Para las razones detrás de la desaparición de los alcaldes mayores de Macha en los años 1940, ver Platt y Molina (2018, cap. III).

56 Para el testimonio del escribano de Santos Marka Tola, ver Condori Chura y Ticona Alejo (1992). 
nacional, una política que se basaba en la idea de una recuperación parcial de las leyes de Indias. Pero al mismo tiempo, los curacas andaban a ciudades, pueblos y oficinas de abogados en busca de una justicia republicana, y mantenían contacto con un abanico de instancias jurídicas - aún poco estudiadas - que les enseñaban el contenido de documentos relevantes que ellos mismos no sabían leer.

Después de 1952, el bilingüismo criollo empezó a menguar. Los hijos de los terratenientes ya no aprendían el idioma de sus ex colonos. En cambio, muchos campesinos empezaban a volverse bilingües en quechua/aimara y en castellano, aunque en el norte de Potosí muchos ayllus seguían monolingües en aimara o quechua (a veces hablando los dos). Pero al mismo tiempo, los tres idiomas fueron utilizados en las escuelas y las radios, ambas instituciones con canales bilingües.

Entonces, la historia del curacazgo en la segunda mitad del siglo se desarrollaría bajo un doble signo. Por una parte, los hijos del curaca aprendían las técnicas de escribir en castellano notarial, y de gobernar en base al manejo del archivo. Aunque Agustín estaría marginado entre 1954 y 1961 por el subprefecto movimientista de Colquechaca, que quería secuestrar la Contribución para la administración provincial, el curaca pudo recuperar su cargo entre 1961 y 1981 con el apoyo de una Prefectura ansiosa de fortalecer el presupuesto del Departamento con la Contribución de los comunarios, y con plena confianza en la eficacia de Agustín como recaudador.

En este período, el Cabildo de Salinas (ayllu Alacoyana) produjo un informe en castellano que resumía el pacto tradicional con el Estado y planteaba su conservación como objetivo político de los campesinos:

Sin embargo, se iba reduciendo la jurisdicción de Agustín y Gregorio Carbajal, hasta encontrarse circunscrita, en los años 1980, a solo seis de los siete cabildos de su propio ayllu Alacollana, junto con un par de cabildos de los ayllus vecinos Sullcavi y Huaracata (Platt y Molina, 2018, caps. II y IV-VI). En 1981, Agustín Carbajal presentó su renuncia por vejez al prefecto de Potosí y fue reemplazado por su hijo Gregorio.

Pero paralelamente con la historia del curacazgo, desde 1953 se establecían las centrales y las subcentrales del sindicalismo movimientista rural, implantadas en el campo norpotosino después de la Revolución por mineros, excolonos y mosos del MNR con fines de movilización política, control del campo y del sufragio, y «desarrollo» agrícola (formación de cooperativas y tecnificación). Fueron extendidas hacia la provincia Chayanta Colquechaca a través de dirigentes locales que funcionaban como agentes del movimientismo (Platt, 2016[1982]). Esta historia también ha dejado huellas en el Archivo del Curacazgo de Macha Alasaya. 


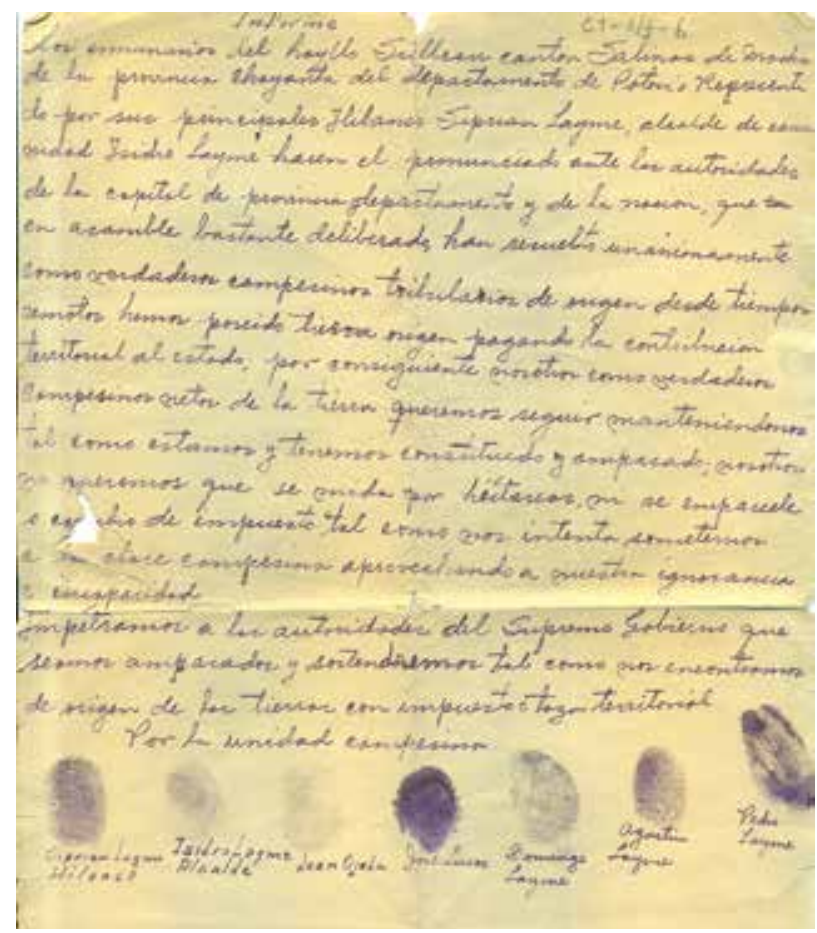

Transcripción: «Informe.

Los comunarios del hayllo Sullcavi canton Salinas de Macha de la provincia Chayanta del departamento de Potosí representado por sus principales Hilanco Siprian Layme; alcalde de comunidad Isidro Laymi hacen el pronunciado ante las autoridades de la capital de provincia departamento y de la nacion; que en asamblea bastante deliberado han resuelto unanimamente como verdaderos campesinos tributarios de origen desde tiempos remotos hemos poseido tierra origen pagando la contribución territorial al estado; por consiguiente nosotros como verdaderos campesinos netos de la tierra queremos seguir manteniendonos tal como estamos y tenemos constituydo y amparado; nosotros no queremos que se mida por hectareas, ni se emparcele a cambio de impuesto tal como nos intenta someternos a la clase campesina aprovechando a nuestra ignorancia e incapacidad; impetramos a las autoridades del Supremo Gobierno que seamos amparados y sostendremos tal como nos encontramos de origen de las tierras con impuesto o taza territorial.

Por la unidad campesina.

Siprian Laymi, Jilanco. Isidro Laymi, Alcalde. Juan Ojeda, José Lázaro, Domingo Laymi, Agustin Laymi, Pedro Laymi».
Lámina 9: El «pacto de reciprocidad» entre ayllu y Estado. Informe del ayllu Sullcavi, cantón [Cabildo] Salinas. S/f [ca. 1968]. Ver Platt y Molina (2018, Catálogo, C1-S/F 6). 
Al fin del período de las dictaduras (1964-1982), la Federación Especial del Norte de Potosí (oficialista) fue reemplazada por la Federación Única (inicialmente independiente) formada por Jenaro Flores en la breve apertura democrática de 1971, pero proscrita bajo los Generales Banzer (1971-1978) y García Mesa (1980-1981). Después de una breve reaparición en 1978-1980, reapareció en 1982 y fue dirigida desde Llallagua como parte constituyente de la Confederación Sindical Única de Trabajadores Campesinos de Bolivia (CSUTCB), con sede en La Paz.

Y fue en 1982 cuando una nueva subcentral de la Federación Única se implantó en «Pampa Colorada», lugar perteneciente al mismo cabildo Pichichua (ayllu Alacollana) donde vivían los curacas de Macha Alasaya. El nuevo dirigente local Agustín Acho llegó a ser un poderoso caudillo regional. Los dirigentes eran letrados, muchos de ellos formados en el Instituto Politécnico «Tomás Katari» (IPTK) de Ocurí (cerca de la frontera de Macha con Ravelo [Moromoro]), que se había creado por el MIR (Movimiento de la Izquierda Revolucionaria) en 1976 con dinero belga y holandés, y después de 1985 fue dirigido por el MBL (Movimiento de Bolivia Libre). Ambos partidos se oponían a las dictaduras, pero se dirigían en Ocurí por políticos jóvenes que consideraban a los ayllus (si es que pensaban sobre ellos) como reliquias del pasado, a la vez que querían asegurarse el voto campesino en las elecciones regionales. Los dirigentes sindicales terminarían subvirtiendo y, con la «Ley de Participación Popular» (obra del MNR y Goni Sánchez de Lozada), extinguiendo al curacazgo quechua-hablante de Macha Alasaya, cuando en 1994 los dirigentes aceptaron la renuncia definitiva del curaca don Gregorio Carbajal.

Para fines del siglo XX, entonces, los cabildos y ayllus de Macha se encontraban dominados por una poderosa organización rival dirigida desde el pueblo de Macha, y de Colquechaca, Llallagua y La Paz: bilingüe pero implantada ${ }^{57}$. Desde poco antes de la renuncia de Gregorio Carbajal, la tasa fue nuevamente entregada, ya no a la Prefectura, sino como «derramas» (cuotas) a los sindicatos. Así, para inicios del siglo XXI, la sociedad relativamente autónoma de los ayllus —basada durante el siglo XX en la democracia directa, los cabildos y el «pacto»

57 Para la historia de los sindicatos en otras provincias norpotosinas, ver Harris y Albó (1975); Rivera Cusicanqui (1984). Para la negociación y la rivalidad entre los curacas y ayllus de Macha y sucesivos dirigentes sindicales en la provincia Chayanta Colquechaca, ver Platt y Molina (2018, especialmente caps. IV-VI). 
con el Estado, y defendida mediante la «literacidad administrada» de los curacas con sus escribanos bilingües e hijos letrados - había llegado a un callejón sin salida. Hoy en día se presenta como una debilitada y encubierta dependencia de los sindicatos ${ }^{58}$.

Sevilla, abril de 2018

\section{REFERENCIAS BIBLIOGRÁFICAS}

Ari, Waskar (2014). Earth Politics. Religion, Decolonization and Bolivia's Indigenous Intellectuals. Durham y Londres: Duke University Press.

Arías, Juan Félix [= Waskar Ari] (1994). Historia de una esperanza: los apoderados espiritualistas de Chuquisaca, 1936-1964. La Paz: Aruyiwiri.

Ari-Chachaki, Waskar (2008-2010). Between Indian Law and Qullasuyu Nationalism. Gregorio Titiriku and the Making of AMP Indigenous Activists, 1921-1964. Revista de Estudios Bolivianos, 15-17 (Pittsburgh), (pp. 91-113).

Barragán, Rossana (1999). Indios, mujeres y ciudadanos. Legislación y ejercicio de la ciudadanía en Bolivia (siglo XIX). La Paz: Fundación Diálogo.

Barragán, Rossana (2009). La representación territorial y la ciudadanía en el sistema directo e indirecto (Bolivia 1825-1880). Anuario de Estudios Bolivianos, 13, 71-118.

Código de Procederes Santa Cruz [1833]. Consultado en línea por el Sistema de Información Legal del Estado Plurinacional (SILEP): http://www.silep.gob.bo/silep/ masterley/123841

Condori Chura, Leandro y Alejo Esteban Ticona (1992). El escribano de los caciques apoderados: Kasikinakan purirarunakan qillqiripa. La Paz: HISBOL/THOA.

Cummins, Tom y Joanne Rappaport (2012). Beyond the Lettered City: Indigenous Literacies in the Andes. Durham, NC: Duke University Press.

Cunill, Caroline (e.p.). Tribunales itinerantes, justicia local y mediación lingüística en Yucatán (siglo XVI). En Caroline Cunill y Luis Miguel Glave Testino (eds.), Las lenguas indígenas en los tribunales de América Latina: intérpretes, mediación

58 Ver, sin embargo, Platt y Molina (2018, Cap.VI, Postscriptum) para el nombramiento en 2016 del mismo dirigente sindical de Pampa Colorada, Agustín Achu, como nuevo curaca de Macha Alasaya después de la muerte de Gregorio Carbajal en diciembre de 2014. Junto con un nuevo curaca de Majasaya, ambos han sido posesionados formalmente en sus cargos por el subprefecto de la provincia Chayanta Colquechaca. No sabemos la fuerza de su apoyo entre los cabildos y ayllus de Macha. 
y justicia (siglos XVI-XXI). Bogotá: Instituto Nacional Colombiano de Antropología e Historia.

Cunill, Caroline y Luis Miguel Glave Testino (comps.) (e.p.). Las lenguas indigenas en los tribunales de América Latina: intérpretes, mediación y justicia (siglos XVIXXI). Bogotá: Instituto Nacional Colombiano de Antropología e Historia.

Dandler, Jorge (1969). El sindicalismo campesino en Bolivia: los cambios estructurales en Ucureña. México: Instituto Indigenista Interamericano.

De la Puente Luna, José Carlos (2016). En lengua de indios y en lengua española: escribanos indígenas, cabildos de naturales y escritura alfabética en el Perú colonial. En Ana Luisa Izquierdo de la Cueva (ed.), Desafíos metodológicos para la historia de los pueblos indígenas (pp. 51-113). México D.F.: Universidad Autónoma de México.

Derrida, Jacques (1997). Mal de Archivo. Una impresión freudiana. Madrid: Trotta.

Espinoza Soriano, Waldemar (1960). El «Alcalde Mayor» indígena en el virreinato del Perú. Anuario de Estudios Americanos, t. XVII (Sevilla), 183-300.

Fishman, Joshua (1967). Bilingualism with and without Diglossia: Diglossia with and without Bilingualism. En John Macnamara (comp.), Problems of Bilingualism, Journal of Social Issues 23(2), 29-38.

Gardner-Chloros, Penelope (1995). Code-switching in community, regional and national repertoires: the myth of the discreteness of linguistic systems. En Lesley Monroy y Pieter Muysken (comps.), One Speaker, Two Languages. Cross-disciplinary perspectives on code-switching (pp. 68-88). Cambridge: Cambridge University Press.

Glave, Luis Miguel (1990). Los campesinos leen su historia: un caso de identidad recreada y creación colectiva de imágenes (Los comuneros canas de Cusco, Perú, 1920-1930). Revista de Indias, 50(190), 809-849.

Glave, Luis Miguel (2008). Cultura política, participación indígena y redes de comunicación en la crisis colonial. El Virreinato peruano, 18091814. Historia Mexicana, LVIII, 369-426.

Glave Testino, Luis Miguel (e.p.). Simiachi: el intérprete o «lengua» en la Audiencia de Lima (siglos XVI-XVIII). En Caroline Cunill y Luis Miguel Glave Testino (eds.), Las lenguas indígenas en los tribunales de América Latina: intérpretes, mediación y justicia (siglos XVI-XXI). Bogotá: Instituto Nacional Colombiano de Antropología e Historia.

Gordillo, José (2000). Campesinos revolucionarios en Bolivia: identidad, territorio y sexualidad en el Valle Alto de Cochabamba, 1952-1964. La Paz: Universidad de la Cordillera, Plural. 
Gotkowitz, Laura (2007). A Revolution for our Rights. Indigenous Struggles for Land and Justice in Bolivia, 1880-1952. Durham y Londres: Duke University Press.

Guerrero, Andrés (2010). Administración de poblaciones, ventriloquía y transescritura. Lima/Quito: Instituto de Estudios Peruanos/Flacso.

Gumperz, John J. (1982). Discourse Strategies. Cambridge: Cambridge University Press.

Harris, Olivia y Xavier Albó (1975). Monteras y guardatojos: campesinos y mineros en el norte de Potosí. La Paz: Centro de Investigación y Promoción del Campesinado.

Jurado, Carolina (2010). Don Pedro de Dueñas, indio lengua. Un estudio de caso de la interpretación lingüística andino-colonial en el siglo XVII. Anuario del Archivo y Biblioteca Nacional de Bolivia, 16, 285-309.

López, Luis Enrique (1994). Balance y perspectivas de la educación intercultural bilingüe. En Educación Bilingüe e Intercultural. Reunión Anual de Etnología 1994 (Tomo II). Serie: Anales de la Reunión Anual de Etnología. Museo Nacional de Etnología y Folclore. La Paz.

Mamani Condori, Carlos (1991). Taraqu, 1866-1935: Masacre, Guerra y «Renovación» en la biografía de Eduardo L. Nina Qhispe. La Paz: Aruwiyir.

Platt, Tristan (1984). Liberalism and ethnocide in the southern Andes, History Workshop Journal $N^{\circ} 17$, Routledge and Kegan Paul. London [13 pp.] (Versión española en Autodeterminación, 17. La Paz, 1991).

Platt, Tristan (1987). The Andean Experience of Bolivian Liberalism, 1825-1900: Roots of Rebellion in $19^{\text {th }}$-Century Chayanta (Potosí). En Steve Stern (comp.), Rebellion, Resistance and Consciousness in the Andean Peasant World, 18th-20th centuries (pp. \#) Madison: University of Wisconsin Press. [Versión española en Stern (comp.), Rebelión, resistencia y conciencia en el mundo rural andino (ss. XVIII-XX). Lima: Instituto de Estudios Peruanos, 1991].

Platt, Tristan (2009). Tributo y ciudadanía en Potosí, Bolivia. Consentimiento y libertad entre los Ayllus de la Provincia de Porco, 1830-1840. En Pilar García Jordán (comp.), Dinámicas de poder local en América Latina (pp. 109-163). Barcelona: Universitat de Barcelona.

Platt, Tristan (2012). Between routine and rupture: the Archive as field event. En SAGE Companion to Anthropology. Londres - New York - New Delhi: SAGE [Versión española en Carlos Zanolli, Julia Costilla, Dolores Estruch, Alejandra Ramos (comps.), Los estudios andinos hoy: Práctica intelectual y estrategias de investigación (pp. 21-37). Rosario: Prohistoria Ediciones, 2013].

Platt, Tristan (2014). Un archivo campesino como «Acontecimiento de Terreno». Fuentes. Revista de la Biblioteca y Archivo Histórico de la Asamblea Legislativa Plurinacional, 33, 6-18. La Paz. 
Platt, Tristan (2018). «Un Ceque de la Muerte». Milagros, memoria y ruptura en San Bartolomé de Carata, Macha, siglos 16-21. En María de los Angeles Muñoz (comp.), Interpretando huellas. Arqueología, etnohistoria y etnografía en los Andes y sus tierras bajas. Cochabamba.

Platt, Tristan, Thérèse Bouysse-Cassagne, Olivia Harris, Thierry Saignes (2011[2006]). Qaraqara-Charka. Historia antropológica de una confederación aymara. La Paz: Plural Editores, Instituto Francés de Estudios Andinos, Universidad de St Andrews, Universidad de Londres.

Platt, Tristan y Gonzalo Molina Echeverría (2018). Defendiendo el techo fiscal, 19301994. Curacas, ayllus y sindicatos en Macha durante el siglo XX. Catálogo, índices y CD del Archivo del Curacazgo de Macha Alasaya (ACMA). Colección documental de la Familia Carbajal. La Paz: Biblioteca y Archivo Histórico de la Asamblea Legislativa Plurinacional, Vice-Presidencia del Estado Plurinacional / Centre of Amerindian, Latin American and Caribbean Studies, University of St Andrews, Escocia.

Plaza, Pedro (1994). Perspectivas del bilingüismo en la sociedad jerárquica. En Educación Bilingüe e Intercultural. Reunión Anual de Etnología 1994 (Tomo II). Serie: Anales de la Reunión Anual de Etnología. Museo Nacional de Etnología y Folclore. La Paz.

Quintana Taborga, Juan Ramón (1998). Soldados y ciudadanos. Un estudio crítico sobre el servicio militar obligatorio en Bolivia. La Paz: PIEB.

Rivera Cusicanqui, Silvia (1984). Oprimidos pero no vencidos: luchas del campesinado aymara y qhechwa de Bolivia, 1900-1980. La Paz: HISBOL.

Rivera Cusicanqui, Silvia (1991). «Pedimos la revisión de límites». Un episodio de la incomunicación de castas en el movimiento de los caciques apoderados de los Andes bolivianos. En Frank Salomon y Segundo Moreno (comps.), Reproducción y transformación de las sociedades andinas, siglos XVI-XX, tomo 2 (pp. 603-652). Quito: Abya-Yala.

Rivera Cusicanqui, Silvia (1978). El mallku y la sociedad colonial en el siglo XVII: el caso de Jesús de Machaca. Avances 1. La Paz.

Rodríguez, Lorena (2016). Los indígenas de Tucumán y Catamarca durante el período republicano. Buscando sus rastros en expedientes judiciales. Revista Historia y Justicia, 7. Santiago de Chile.

Salomon, Frank y Mercedes Niño-Murcia (2011). The Lettered Mountain. A Peruvian Village's Way with Writing. Durham y Londres: Duke University Press.

Salomon, Frank (2002). Unethnic Ethnohistory: On Peruvian Peasant Historiography and Ideas of Autocthony. Ethnohistory, 49(3), 475-506. Duke University Press. 
Serulnikov, Sergio (2006). Conflictos sociales e insurgencia en el mundo colonial andino. El norte de Potosí, siglo XVIII. Buenos Aires: Fondo de Cultura Económica.

Serulnikov, Sergio (2012). Revolución en los Andes. La era de Túpac Amaru. Buenos Aires: Sudamericana.

Taller de Historia Oral Andino (1984). El indio Santos Marka T'ula, Cacique Principal de los ayllus de Qallapa y apoderado general de las comunidades originarias de la República. La Paz: THOA.

Urcullo, Andrea (2015). Siguiendo los pasos de Cádiz. Las primeras normas procedimentales en material de justicia en la República de Bolivia (1825-1832). Revista Andina, 52. Cusco: Centro de Estudios Regionales Andinos Bartolomé de Las Casas.

Urton, Gary (2017). Inka History in Knots. Reading Khipus as Primary Sources. Austin: Texas University Press.

Zavala, Virginia, Mercedes Niño-Murcia y Patricia Ames (eds.) (2004). Escritura y sociedad: nuevas perspectivas teóricas y etnográficas. Lima: PUCP, Universidad del Pacífico. 